OPEN ACCESS

Edited by:

Maria E. Mycielska,

University Medical Center

Regensburg, Germany

Reviewed by:

Isabel Soto-Cruz,

Universidad Nacional Autónoma

de México, Mexico

Marie-Pierre Golinelli,

UPR 2301 Institut de Chimie des

Substances Naturelles (ICSN CNRS),

France

*Correspondence:

Jacinta Serpa

jacinta.serpa@nms.unl.pt

Specialty section:

This article was submitted to

Molecular and Cellular Oncology,

a section of the journal

Frontiers in Cell and Developmental

Biology

Received: 08 June 2021

Accepted: 13 July 2021

Published: 11 August 2021

Citation:

Nunes SC, Ramos C, Santos I,

Mendes C, Silva F, Vicente JB,

Pereira SA, Félix A, Gonçalves LG and

Serpa J (2021) Cysteine Boosts

Fitness Under Hypoxia-Mimicked

Conditions in Ovarian Cancer by

Metabolic Reprogramming.

Front. Cell Dev. Biol. 9:722412.

doi: 10.3389/fcell.2021.722412

\section{Cysteine Boosts Fitness Under Hypoxia-Mimicked Conditions in Ovarian Cancer by Metabolic Reprogramming}

\author{
Sofia C. Nunes ${ }^{1,2}$, Cristiano Ramos ${ }^{1,2}$, Inês Santos ${ }^{1,2}$, Cindy Mendes ${ }^{1,2}$, Fernanda Silva ${ }^{1,2}$, \\ João B. Vicente ${ }^{3}$, Sofia A. Pereira ${ }^{1}$, Ana Félix ${ }^{1,2}$, Luís G. Gonçalves ${ }^{3}$ and Jacinta Serpa ${ }^{1,2 *}$ \\ ${ }^{1}$ Centro de Estudos de Doenças Crónicas, NOVA Medical School/Faculdade de Ciências Médicas, Universidade Nova \\ de Lisboa, Lisbon, Portugal, ${ }^{2}$ Instituto Português de Oncologia de Lisboa Francisco Gentil, Lisbon, Portugal, ${ }^{3}$ Instituto \\ de Tecnologia Química e Biológica António Xavier, Universidade Nova de Lisboa, Oeiras, Portugal
}

Among gynecologic malignancies, ovarian cancer is the third most prevalent and the most common cause of death, especially due to diagnosis at an advanced stage together with resistance to therapy. As a solid tumor grows, cancer cells in the microenvironment are exposed to regions of hypoxia, a selective pressure prompting tumor progression and chemoresistance. We have previously shown that cysteine contributes to the adaptation to this hypoxic microenvironment, but the mechanisms by which cysteine protects ovarian cancer cells from hypoxia-induced death are still to be unveiled. Herein, we hypothesized that cysteine contribution relies on cellular metabolism reprogramming and energy production, being cysteine itself a metabolic source. Our results strongly supported a role of xCT symporter in energy production that requires cysteine metabolism instead of hydrogen sulfide $\left(\mathrm{H}_{2} \mathrm{~S}\right)$ per se. Cysteine degradation depends on the action of the $\mathrm{H}_{2} \mathrm{~S}$-synthesizing enzymes cystathionine $\beta$-synthase (CBS), cystathionine $\gamma$-lyase (CSE), and/or 3mercaptopyruvate sulfurtransferase (MpST; together with cysteine aminotransferase, CAT). In normoxia, CBS and CSE inhibition had a mild impact on cysteine-sustained ATP production, pointing out the relevance of CAT + MpST pathway. However, in hypoxia, the concomitant inhibition of CBS and CSE had a stronger impact on ATP synthesis, thus also supporting a role of their hydrogen sulfide and/or cysteine persulfidesynthesizing activity in this stressful condition. However, the relative contributions of each of these enzymes (CBS/CSE/MpST) on cysteine-derived ATP synthesis under hypoxia remains unclear, due to the lack of specific inhibitors. Strikingly, NMR analysis strongly supported a role of cysteine in the whole cellular metabolism rewiring under hypoxia. Additionally, the use of cysteine to supply biosynthesis and bioenergetics was reinforced, bringing cysteine to the plateau of a main carbon sources in cancer. Collectively, this work supports that sulfur and carbon metabolism reprogramming underlies the adaptation to hypoxic microenvironment promoted by cysteine in ovarian cancer.

Keywords: carbon source, cysteine, hypoxia, ovarian cancer, hydrogen sulfide, cystine, bioenergetics, microenvironment 


\section{INTRODUCTION}

Despite all the progresses developed in prevention and new treatment approaches, cancer corresponds to the second leading cause of death worldwide (Fitzmaurice et al., 2015). Ovarian cancer is not an exception to this scenario, being expected, in 2020, 0.28 million new cases and 0.18 million ovarian cancer deaths worldwide (Ferlay et al., 2013). The late diagnosis together with resistance to conventional therapy represent the major causes for the poor prognosis of this disease (Jayson et al., 2014).

Epithelial ovarian cancer (EOC) includes most (90\%) ovarian malignancies (Bast et al., 2009; Desai et al., 2014) that can be classified based on histopathology and molecular/genetic features, being mainly classified as serous low-grade (LG-OSC, $<5 \%$ ) and high-grade (HG-OSC, 70\%), endometrioid (OEC, $10 \%$ ), clear cell (OCCC, 10\%) and mucinous (OMC, 3\%) (Prat, 2012; Reid et al., 2017).

As a solid tumor grows, cancer cells are exposed to varying oxygen tensions and to different degrees of hypoxia, being these oxygen fluctuations strongly linked to oxidative stress (Fruehauf and Meyskens, 2007; Saed et al., 2017) and known to be responsible for tumor progression and resistance to therapy (Vaupel and Mayer, 2007; Semenza, 2012). In ovarian cancer, oxidative stress was already associated with the pathogenesis of the disease (Senthil et al., 2004; Saed et al., 2017), indicating that ovarian cancer cells present mechanisms that allow them to cope with the harmful oxidative conditions. We disclosed that cysteine facilitates the adaptation of ovarian cancer cells to hypoxic environments and to carboplatin-induced death (Nunes et al., 2018a,b). Moreover, the relevance of cysteine in the clinical context of ovarian cancer was also corroborated, since ascitic fluid from ovarian cancer patients an important compartment of tumor microenvironment showed cysteine as the prevalent thiol and because cysteine levels were also altered in serum from patients with ovarian tumors (Nunes et al., 2018b). Cysteine role in cancer cells survival was already associated with its role as a precursor of the antioxidant glutathione (GSH) (Schnelldorfer et al., 2000; Balendiran et al., 2004; Lopes-Coelho et al., 2016) and due to hydrogen sulfide $\left(\mathrm{H}_{2} \mathrm{~S}\right)$ generation (Bhattacharyya et al., 2013; Szabo et al., 2013; Pan et al., 2015; Panza et al., 2015; Sen et al., 2015; Gai et al., 2016; Szczesny et al., 2016) by cysteine catabolism through the activity of the enzymes cystathionine $\beta$-synthase (CBS), cystathionine $\gamma$-lyase (CSE), and/or 3-mercapto-pyruvate sulfurtransferase (MpST) together with cysteine aminotransferase (CAT) (Wang, 2012; Kabil and Banerjee, 2014; Giuffrè and Vicente, 2018; Hipólito et al., 2020). CBS, CSE, and MpST also catalyze the cyst(e)ine-dependent production of cysteine persulfide (CysSSH), which in several (patho)physiological contexts affords protection from damaging cysteine oxidation (e.g., Filipovic et al., 2018; Zivanovic et al., 2019; Zuhra et al., 2021). Another recently proposed pathway linking cysteine catabolism with mitochondrial bioenergetics concerns the mitochondrial isoform of cysteinyl-tRNA synthase (CARS2), which converts cysteine into CysSSH and also incorporates persulfidated cysteine into nascent polypeptides (Akaike et al., 2017; Bianco et al., 2019). The uptake of cysteine by cells seems to be preferentially mediated by $\mathrm{xCT}$, a member of the cystine-glutamate transporter xc- system, known to mediate the uptake of cystine, the oxidized form of cysteine (Sato et al., 2000). Interestingly, it was reported that xCT was associated with intracellular GSH level and with cisplatin resistance in human ovarian cancer cell lines (Okuno et al., 2003). More recently, xCT has been implicated as part of highly favorable metabolic cancer phenotype, presenting increased capacity of ATP generation amongst other features pivotal for cancer cells survival and chemoresistance (Polewski et al., 2016; Jourdain et al., 2021).

Here, we aimed to address the mechanism by which cysteine protects ovarian cancer cells from hypoxia-induced death, hypothesizing that in addition to its role as GSH precursor, cysteine contributes to cell bioenergetics and biosynthesis under hypoxic conditions, as both a donor of $\mathrm{H}_{2} \mathrm{~S}$ and as a carbon source. To test this hypothesis, we used two different ovarian cancer cell lines derived from two different histological types. ES2 cells correspond to an ovarian clear cell carcinoma (OCCC), an uncommon but highly chemoresistant histotype, and OVCAR3 cells correspond to a high-grade ovarian serous carcinoma (HG-OSC, the most frequent histotype), which usually acquires resistance during chemotherapy (Goff et al., 1996; Sugiyama et al., 2000; Cooke et al., 2011; Beaufort et al., 2014).

\section{MATERIALS AND METHODS}

\section{Cell Culture}

Cell lines from OCCC (ES2; CRL-1978) and HG-OSC (OVCAR3; HTB-161) were obtained from American Type Culture Collection (ATCC). Cells were maintained at $37^{\circ} \mathrm{C}$ in a humidified 5\% $\mathrm{CO}_{2}$ atmosphere, and cultured in Dulbecco's Modified Eagle medium (DMEM, 41965-039, Gibco, Life Technologies), containing $4.5 \mathrm{~g} / \mathrm{L}$ of D-glucose and $0.58 \mathrm{~g} / \mathrm{L}$ of L-glutamine, 1\% FBS (S 0615, Merck), 1\% antibiotic-antimycotic (P06-07300, PAN Biotech) and 0.1\% gentamicin (15750-060, Gibco, Life Technologies). Cells were exposed either to $0.402 \mathrm{mM}$ L-cysteine (102839, Merck) and/or to hypoxia induced with $0.1 \mathrm{mM}$ cobalt chloride $\left(\mathrm{CoCl}_{2}\right)$ (C8661, Sigma-Aldrich) as previously (Nunes et al., 2018a,b).

Prior to any experiment, cells were synchronized under starvation (culture medium without FBS) for $8 \mathrm{~h}$ at $37^{\circ} \mathrm{C}$ and $5 \% \mathrm{CO}_{2}$.

\section{ATP Quantification}

To test the effect of $\mathrm{xCT}$ inhibition on ATP levels, cells $\left(5 \times 10^{5}\right.$ or $2.5 \times 10^{5}$ cells/well) were seeded in 6-well white plates in hypoxia-mimic conditions induced with $0.1 \mathrm{mM} \mathrm{CoCl}_{2}$ and challenged with $0.25 \mathrm{mM}$ sulfasalazine (S0883, Sigma), an xCT inhibitor (Gout et al., 2001). After $24 \mathrm{~h}$, the medium was replaced and the challenging/stimulatory conditions reset. Cells were collected at $48 \mathrm{~h}$ after stimulation.

To test the effect of the enzymes involved in cysteine metabolism on ATP synthesis, cells $\left(5 \times 10^{5}\right.$ or $2.5 \times 10^{5}$ cells/well) were seeded in 6-well plates and cultured in control condition and exposed to $0.402 \mathrm{mM}$ L-cysteine and/or $0.100 \mathrm{mM}$ 
$\mathrm{CoCl}_{2}$. The previous conditions were combined with $1 \mathrm{mM}$ O-(carboxymethyl)hydroxylamine hemihydrochloride (AOAA, C13408, Sigma) and $3 \mathrm{mM}$ DL-propargylglycine (PAG, P7888, Sigma). AOAA is an inhibitor of both CBS and CSE, whereas PAG is selective toward CSE. After $24 \mathrm{~h}$, the medium was replaced and the challenging/stimulatory conditions reset. Cells were collected at 16 and $48 \mathrm{~h}$ after stimulation. This assay was also performed with cell collection after $2 \mathrm{~h}$ of experimental conditions. In this case, $5 \times 10^{5}$ cells were seeded in 6-well white plates for both ES2 and OVCAR3 cells.

To investigate the effect of cyst(e)ine and $\mathrm{NaHS}\left(\mathrm{H}_{2} \mathrm{~S}\right.$ donor) on ATP synthesis upon xCT inhibition, cells $\left(5 \times 10^{5}\right.$ or $2.5 \times 10^{5}$ cells/well) were seeded in 6-well plates and exposed to hypoxia induced with $0.1 \mathrm{mM} \mathrm{CoCl} 2$ with and without $0.402 \mathrm{mM}$ L-cysteine combined with $0.25 \mathrm{mM}$ sulfasalazine, $30 \mu \mathrm{M}$ NaHS (161527 Sigma-Aldrich) or both. After $24 \mathrm{~h}$, the medium was replaced and the challenging/stimulatory conditions reset. Cells were collected at $48 \mathrm{~h}$ after stimulation. This assay was also performed with cell collection after $1 \mathrm{~h}$ of experimental conditions. In this case, $5 \times 10^{5}$ cells were seeded in 6 -well white plates for both ES2 and OVCAR3 cells.

Cells were scraped with cold PBS containing $2 \mathrm{mM}$ EDTA and homogenized in 1\% Non-idet P-40 (NP-40) lysis buffer (1\% NP40 N-6507 Sigma, and $1 \times$ protease inhibitor, SIGMAFAST ${ }^{\mathrm{TM}}$ Protease inhibitor cocktail tablets S8830, Sigma) on ice for $30 \mathrm{~min}$ and centrifuged at $20,000 \times g$ for $5 \mathrm{~min}$ at $4^{\circ} \mathrm{C}$. Protein was quantified and the same amount of total protein was used within each assay, in a range between 2.5 and $10 \mu \mathrm{g}$. ATP determination kit (A22066, Molecular probes) was used in accordance with the manufacturer's instructions. The measurements were performed using the Luciferase protocol in a VIKTOR3 plate reader (PerkinElmer), using the Wallac 1420 software, version 3.0 (Luminometry, Luciferase FIR protocol). ATP concentration was determined against an ATP calibration curve, within the range between 0 and $30 \mu \mathrm{M}$.

\section{Immunofluorescence Analysis}

Cells $\left(1 \times 10^{5}\right.$ cells/well $)$ were seeded in 24 -well plates and cultured either in control or stimulated/challenged conditions. After $16 \mathrm{~h}$ of experimental conditions, cells were fixed with $4 \%$ paraformaldehyde for $15 \mathrm{~min}$ at $4^{\circ} \mathrm{C}$ and permeabilized with saponin $0.1 \%$ in PBS-BSA (PBS buffer containing $0.5 \%$, $\mathrm{w} / \mathrm{v}$, bovine serum albumin) for $15 \mathrm{~min}$ at room temperature. Cells were then incubated with anti-xCT (ab175186, abcam) for $30 \mathrm{~min}$ (diluted 1:100 in PBS-BSA) and incubated with secondary antibody for $2 \mathrm{~h}$ at room temperature (Alexa Fluor ${ }^{\circledR}$ 488 anti-rabbit, A-11034, Invitrogen) (1:1000 in PBS-BSA). The protocol was repeated for anti-TOMM20 (1:100 in PBS PBSBSA; ab186734 from abcam) for $2 \mathrm{~h}$ at room temperature and incubated with secondary antibody for $2 \mathrm{~h}$ at room temperature (Alexa Fluor ${ }^{\circledR} 594$ anti-rabbit, A-11037, Invitrogen) (1:1000 in PBS-BSA).

The slides were mounted in VECTASHIELD media with 4'-6-diamidino-2-phenylindole (DAPI) (Vector Labs) and examined by standard fluorescence microscopy (Zeiss Imajer.Z1
AX10 microscope). Images were acquired and processed with CytoVision software.

\section{Western Blotting Analysis of Mitochondria Extracts}

Cells $\left(7 \times 10^{6}\right.$ cells/flask $)$ were cultured in $150 \mathrm{~cm}^{2}$ culture flasks and submitted to control condition and to $0.402 \mathrm{mM}$ L-cysteine and/or $0.1 \mathrm{mM} \mathrm{CoCl} 2$. Cells were collected after $16 \mathrm{~h}$ of experimental conditions, and mitochondria were isolated with the Mitochondria Isolation Kit for profiling cultured cells (MITOISO2, Sigma). Briefly, cells were scraped, centrifuged for 5 min at $600 \times g$ and washed in ice cold PBS. The cell pellet was resuspended in $650 \mu \mathrm{L}$ of Lysis Buffer, according to the manufacturer's instructions.

The mitochondrial lysates were centrifuged at $20,817 \times g$ for $5 \mathrm{~min}$ at $4^{\circ} \mathrm{C}$ and total protein concentration was determined based on the Bradford method (500-0006, Bio Rad). Western blotting for $\mathrm{xCT}$ and TOMM20 detection was performed with $15 \mu \mathrm{g}$ of total protein, whereas for MpST, $20 \mu \mathrm{g}$ of total protein were used. TOMM20 was used as a mitochondrial endogenous control.

Total protein in SDS-PAGE gels was transferred to PVDF membranes by semi-dry transfer. Membranes were blocked with PBS-milk (PBS containing 5\% non-fat skimmed powdered milk) incubated with anti-xCT (1:1000 in PBS-milk; ab175186 from abcam) or anti-MpST (1:250 in PBS-milk; HPA001240 from Sigma) at $4^{\circ} \mathrm{C}$ with stirring, overnight. The membranes were then washed three times, for $5 \mathrm{~min}$, with PBS $1 \times 0.1 \%(\mathrm{v} / \mathrm{v})$ Tween 20, and further incubated with secondary antibody (anti-rabbit 1:5,000 in PBS-milk; 31460 from Thermo Scientific) for $2 \mathrm{~h}$ at room temperature. For the membrane that was previously incubated with $\mathrm{xCT}$, the protocol was repeated for anti-TOMM20 (1:1000 in PBS 1x-Milk 5\%; ab186734 from abcam).

\section{Cell Death Analysis}

To test whether the protective effect of cysteine under hypoxia was dependent on $\mathrm{H}_{2} \mathrm{~S}$ production, cells $\left(1 \times 10^{5}\right.$ cells/well) were seeded in 24-well plates. Cells were cultured in control condition and exposed to $0.402 \mathrm{mM}$ L-cysteine and/or hypoxia induced with $0.1 \mathrm{mM} \mathrm{CoCl}$, combined to $1 \mathrm{mM}$ O-(carboxymethyl)hydroxylamine hemihydrochloride (AOAA, C13408, Sigma), to $3 \mathrm{mM}$ of DL-propargylglycine (PAG, P7888, Sigma), or the combination of both. Cells were collected $16 \mathrm{~h}$ after stimulation.

Cells were harvested by centrifugation at $153 \times g$ for $3 \mathrm{~min}$, cells were incubated with $0.5 \mu \mathrm{L}$ FITC-Annexin V (640906, BioLegend) in $100 \mu \mathrm{L}$ annexin $\mathrm{V}$ binding buffer $1 \times 10 \mathrm{mM}$ HEPES ( $\mathrm{pH} 7.4$ ), $0.14 \mathrm{M}$ sodium chloride $(\mathrm{NaCl}), 2.5 \mathrm{mM}$ calcium chloride $\left(\mathrm{CaCl}_{2}\right)$ and incubated at room temperature and in the dark for $15 \mathrm{~min}$. After incubation, samples were rinsed with $0.2 \%(w / v)$ BSA (A9647, Sigma) in PBS and centrifuged at $153 \times g$ for $3 \mathrm{~min}$. Cells were suspended in $200 \mu \mathrm{L}$ of annexin $\mathrm{V}$ binding buffer $1 \times$ and $2.5 \mu \mathrm{L}$ propidium iodide $(50 \mu \mathrm{g} / \mathrm{mL})$ were added. Acquisition was performed in a FACScalibur (Becton Dickinson). Data were analyzed with FlowJo software. 


\section{Nuclear Magnetic Resonance (NMR) Analysis}

To address the metabolic effects of cysteine under normoxia and hypoxia in ES2 and OVCAR3 cells, the levels of several metabolites were measured by ${ }^{1} \mathrm{H}-\mathrm{NMR}$. Cells $\left(6.5 \times 10^{6}\right.$ cells $)$ were seeded in $175 \mathrm{~cm}^{2}$ culture flasks and cultured in control condition and exposed to $0.402 \mathrm{mM} \mathrm{L}$-cysteine and/or hypoxiamimicked conditions induced with $0.1 \mathrm{mM} \mathrm{CoCl}_{2}$. Cells and supernatants were collected at $48 \mathrm{~h}$ after stimulation and stored at $-20^{\circ} \mathrm{C}$.

To follow all the metabolites directly derived from cysteine, cells $\left(6.5 \times 10^{6}\right.$ cells $)$ were seeded in $175 \mathrm{~cm}^{2}$ culture flasks and cultured in control condition and exposed to $0.402 \mathrm{mM}$ $\mathrm{L}$-cysteine and/or hypoxia induced with $0.1 \mathrm{mM} \mathrm{CoCl} 2$. In this assay, a fully U- ${ }^{13}$ C-labeled L-cysteine (CLM-1868-PK, Cambridge Isotopes Laboratories, Inc.) was used. Cells were collected at $48 \mathrm{~h}$ after stimulation and supernatants were collected at $12,24,36$, and $48 \mathrm{~h}$ of incubation and stored at $-20^{\circ} \mathrm{C}$.

Cell extracts were performed with methanol and chloroform to separate organic and aqueous phases. After cold methanol mixture ( $4 \mathrm{~mL}$ methanol/1 g weight pellet), two volumes (vol) of water were added, mixed, and incubated for $5 \mathrm{~min}$ on ice. Chloroform (1 vol) was then added to the sample and mixed. Finally, 1 vol of water was added and samples were incubated for $10 \mathrm{~min}$ on ice, following centrifugation at $1,699 \times g$ for $15 \mathrm{~min}$ at $4^{\circ} \mathrm{C}$. Aqueous (upper) and organic (lower) phases were collected. After extraction of solvents by evaporation, using a Speed Vac Plus Scllon, the samples were suspended on KPi buffer ( $50 \mathrm{mM}, \mathrm{pH} 7.4)$ in deuterated water $\left(\mathrm{D}_{2} \mathrm{O}\right)$ with $4 \%(\mathrm{v} / \mathrm{v})$ sodium azide $\left(\mathrm{NaN}_{3}\right)$ and $0.097 \mathrm{mM}$ of 3-(trimethylsilyl)propionic2,2,3,3-d4 (TSP). Culture supernatants were also diluted in this solution at 1:10 ratio. The $1 \mathrm{H}-\mathrm{NMR}$ (noesypr1d), 13CNMR (zgdc) and 13C-1H-HSQC (hsqcetgpsisp2) was obtained at $25^{\circ} \mathrm{C}$ in an Avance $500 \mathrm{II}+$ (Bruker) spectrometer operating at $500.133 \mathrm{MHz}$, equipped with a $5 \mathrm{~mm}$ TCI(F)-z H-C/N Prodigy cryo-probe. The chemical shifts in aqueous sample were referred to the TSP. Topspin 4.0.7 (Bruker) was used for acquisition and spectra analysis. Compound identification was performed by resorting to the Human Metabolome database (HMDB) ${ }^{1}$ and Chenomx NMR suite software version 8.1 (Chenomx Inc.). Metabolites concentration was determined using Chenomx NMR suite software version 8.1 for $1 \mathrm{H}-\mathrm{NMR}$ spectra (Chenomx Inc.). Quantification of the resonances in 13C-1H-HSQC spectra was done by calculate the $1 \mathrm{D}$ projections and integrate the resonances areas in Topspin 4.0.7, using the TSP resonance was reference.

\section{Statistical Analysis}

All data are presented as the mean \pm SD with the exception of ${ }^{1} \mathrm{H}-\mathrm{NMR}$ data, which are presented as the median with 25 th to 75th percentiles. All the graphics were done using the PRISM software package (PRISM 6.0 for Mac OS X; GraphPad software, United States, 2013) and Microsoft Excel. Assays were performed with at least three biological replicates per treatment, with the

${ }^{1}$ http://www.hmdb.ca/ exception of NMR assay with ${ }^{13} \mathrm{C}$-labeled L-cysteine for which only two biological replicates were performed for the majority of treatments, and hence no statistical analysis was conducted. For comparisons of two groups, a two-tailed independent-samples $t$-test was used. For comparison of more than two groups, one-way analysis of variance (ANOVA) with Tukey's multiplecomparisons post hoc test was used. Statistical significance was established as $p<0.05$. All statistical analyses were performed using the IBM Corp. Released 2013. IBM SPSS Statistics for Macintosh, Version 22.0. Armonk, NY: IBM Corp. software, with the exception of metabolic pathway analysis that was performed with MetaboAnalyst $4.0^{2}$.

\section{RESULTS}

\section{xCT Transporter Localizes in Ovarian Cancer Cells' Mitochondria and Its Inhibition Impairs ATP Production Under Hypoxia, Which Is Further Rescued by Cysteine Supplementation}

We have previously reported that cysteine supplementation was able to protect ovarian cancer cells from hypoxia-induced death (Nunes et al., 2018a,b). Herein, we hypothesized that an increase in intracellular cysteine facilitates this adaptation to hypoxia by an increase in ATP production.

Results show that after $16 \mathrm{~h}$ of experimental conditions, for ES2 cells, ATP levels did not differ among hypoxia with and without cysteine supplementation, and were higher under hypoxia without cysteine compared to normoxia with cysteine $(p=0.017)$ (Figure 1A). With 48 h of experimental conditions, ATP levels were increased under hypoxia without cysteine compared both to hypoxia $(p=0.018)$ and normoxia $(p=0.033)$ with cysteine (Figure 1A).

In OVCAR3 cells, after $16 \mathrm{~h}$ of experimental conditions, no differences were observed among treatments (Figure 1B). However, with $48 \mathrm{~h}$ of experimental conditions, the results were identical to ES2 cells, where cells cultured under hypoxia without cysteine presented higher ATP levels compared both to normoxia $(p=0.008)$ and hypoxia $(p<0.001)$ with cysteine (Figure 1B).

Therefore, after $48 \mathrm{~h}$ of experimental conditions, we observed increased ATP levels in hypoxia-mimicked conditions, which were prevented by cysteine administration in both ES2 and OVCAR3 (Figures 1A,B). These results support that ovarian cancer cells exhibit alternative ways that allow sustaining energy production under hypoxic environments. Since cells cultured under hypoxia without cysteine supplementation also present cysteine in the medium (yet in lower concentrations), and also because cells cultured under hypoxia with cysteine reach higher cellular confluence levels compared to hypoxia without cysteine, we cannot, nevertheless, rule out a role of cysteine in ATP production. Therefore, we further explored the role of $\mathrm{xCT}$, a member of the cystine-glutamate transporter $\mathrm{xc}^{-}$ system, known to mediate the uptake of cystine (Sato et al., 2000)

${ }^{2}$ https://www.metaboanalyst.ca/faces/home.xhtml 

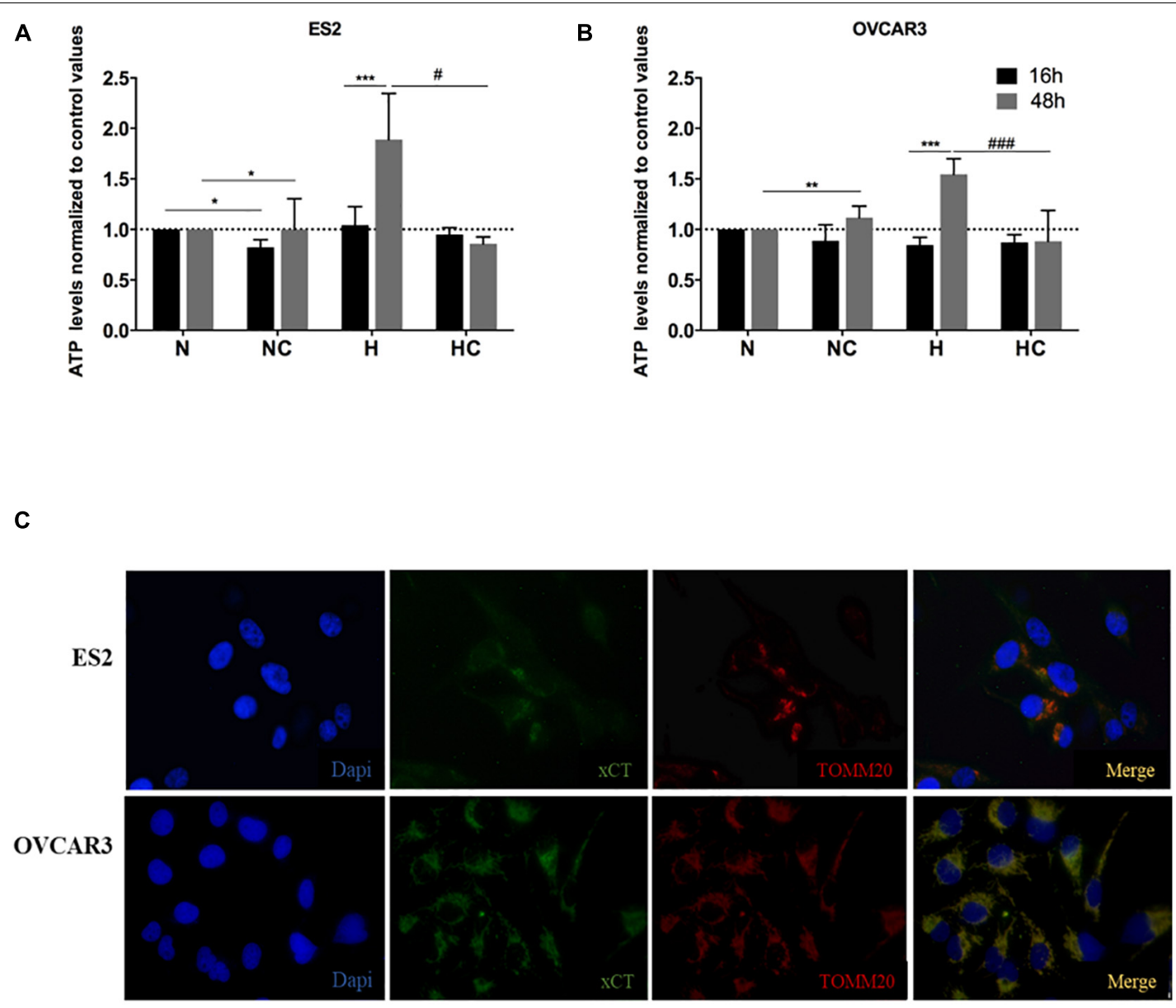

D

\section{E}
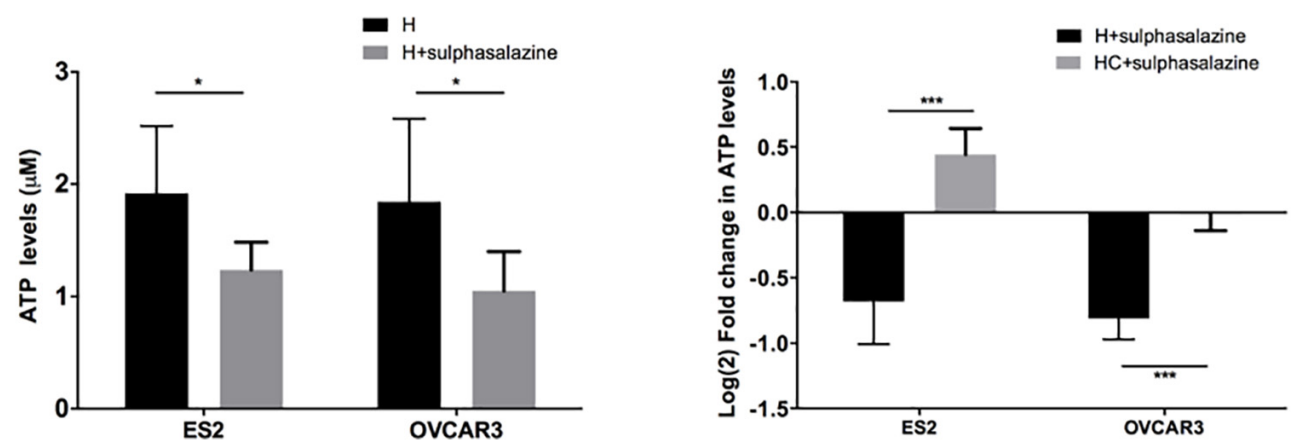

FIGURE 1 | XCT transporter localizes in ovarian cancer cells' mitochondria and its inhibition impairs ATP production under hypoxia, which is further rescued by cysteine. ATP levels normalized to control values (normoxia without cysteine supplementation) for $16 \mathrm{~h}$ and $48 \mathrm{~h}$ of experimental conditions for (A) ES2 cells and (B) OVCAR3 cells. The differences among treatments are pointed in the figure (one-way ANOVA with post hoc Tukey tests. For ES2, $n=6$ for all treatments for $16 \mathrm{~h}$ of experimental conditions and $n=3$ for $48 \mathrm{~h}$ of experimental conditions. For OVCAR3, $n=6$ for all experimental conditions). (C) Immunofluorescence analysis for the xCT transporter and TOMM2O under control conditions (normoxia) for ES2 and OVCAR3 cells $(n=3)$. (D) ATP levels for $48 \mathrm{~h}$ of experimental conditions for ES2 and OVCAR3 cells under hypoxia and in the presence of the XCT inhibitor, sulfasalazine. (E) ATP levels for $48 \mathrm{~h}$ of experimental conditions for ES2 and OVCAR3 cells under hypoxia and in the presence of sulfasalazine and cysteine. The values were normalized to the respective control and $\log _{2}$ fold change was calculated. The differences among treatments are pointed in panels (D,E) (independent-samples $t$-test; $n=6$ for all experimental conditions and for both cell lines). N, normoxia; NC, normoxia with cysteine; H, hypoxia; HC, hypoxia with cysteine. Results are shown as mean \pm SD. ${ }^{\star / \#} p<0.05,{ }^{\star \star / \# \#} p<0.01,{ }^{\star \star \star / / \# \#} p<0.001$. 
(the oxidized form of cysteine that is the predominant status of cysteine extracellularly), on ATP production under hypoxic environments. Thus, we started by addressing if this transporter could localize in ovarian cancer cells' mitochondria thus suggesting a role of cysteine metabolism in ATP production via $\mathrm{Xc}^{-}$system. Immunofluorescence analysis suggested a mitochondrial localization of $\mathrm{xCT}$ in both ES2 and OVCAR3 cells (Figure 1C) that was further confirmed by western blotting analysis mitochondrial extracts (Supplementary Figure 1A). Interestingly, by western blotting with anti-TOMM20 (a mitochondrial marker) results show that ES2 cells present higher levels of TOMM20 under hypoxia compared to the other experimental conditions, whereas OVCAR3 cells seem to present the opposite tendency. As a consequence, the ratio $\mathrm{xCT} / \mathrm{TOMM} 20$ was decreased under hypoxia-mimicked conditions in ES2 cells and increased in OVCAR3 cells (Supplementary Figure 1A).

We then explored the effect of xCT inhibition (with sulfasalazine) in the ability of ovarian cancer cells to produce ATP under hypoxia. Strikingly, $\mathrm{xCT}$ inhibition led to impaired ATP production in both cell lines ( $p=0.038$ for ES2 and $p=0.010$ for OVCAR3) (Figure 1D). Importantly, cysteine was able to rescue this impaired ATP production upon xCT inhibition. Hence, we observed a significant increase in ATP levels upon cysteine supplementation $(p<0.001)$ (Figure 1E).

\section{CBS and CSE Inhibition Does Not Impair ATP Synthesis but Induces Cell Death in ES2 Cells}

Since results suggested that cysteine has a role in ATP synthesis mediated by the xCT transporter, we next measured ATP levels upon CBS and CSE inhibition. Results have shown that after $16 \mathrm{~h}$ of experimental conditions, no differences were found in ATP levels with or without CSE (PAG) and CBS/CSE inhibitors (AOAA) for both ES2 and OVCAR3 cells in any culture condition (Figures 2A-D). As in Figure 1, prolonged (48 h) exposure to hypoxia of both ES2 and OVCAR3 cells resulted in increased ATP production. However, under the same conditions, cysteine decreased ATP levels in both cell lines. Given the dual nature of $\mathrm{H}_{2} \mathrm{~S}$ as an electron supply for the mitochondrial ETC at low concentrations, or as an inhibitor of Complex IV at higher levels, this observation further suggests that exogenous cysteine affects ATP production via CBS/CSE-catalyzed $\mathrm{H}_{2} \mathrm{~S}$ production.

Strikingly, upon exposure to CBS/CSE inhibitors for $48 \mathrm{~h}$, increased ATP levels were observed in all experimental conditions for both ES2 $(\mathrm{N} p=0.002, \mathrm{NC} p=0.001, \mathrm{H}$ $p=0.004, \mathrm{HC} p=0.001)$ and OVCAR3 cells $(\mathrm{N}, \mathrm{NC}$ and HC $p<0.0001$ and $\mathrm{H} p=0.003$ ) with respect to their respective controls (48 h, no inhibitors; Figures 2A-D). In both cell lines exposed for $48 \mathrm{~h}$ to CBS/CSE inhibitors, hypoxia decreased significantly ATP production as compared to normoxia, but cysteine rescued this phenomenon (Figures 2B,D). These observations support the relevance of cysteine degradation on ATP production under hypoxia and put forward the possibility of a compensatory mechanism, e.g., via CAT/MpST or CARS2 to sustain $\mathrm{H}_{2} \mathrm{~S} / \mathrm{CysSSH}$ production under hypoxic conditions.
As ATP levels may increase under stressful conditions (e.g., Zhou et al., 2012) we investigate if there was an increase of cell death in the presence of CSE (PAG) and CBS + CSE (AOAA) inhibitors. We found that for ES2 cells, under normoxia both with and without cysteine supplementation ( $\mathrm{N}$ and $\mathrm{NC}$ ), CSE inhibition induced more cell death compared to joint CSE/CBS inhibition $(p=0.017)$ (Figure 2E). Under hypoxia $(\mathrm{H})$, the combination of both inhibitors induced more cell death compared to their separate administration $(p<0.001)$. Interestingly, under hypoxia with cysteine, PAG alone resulted in increased cell death ( $p=0.038$ compared to the control) as well as in combination with AOAA ( $p=0.002$ compared to the control and $p=0.01$ compared to AOAA alone) (Figure 2E). Regarding OVCAR 3 cells, no differences were observed among treatments, with or without the inhibitors and/or cysteine (Figure 2F).

Together, results indicate that CBS and CSE inhibition, at least at the used doses, is not sufficient to impair ATP production but the inhibition of both enzymes affected ATP synthesis mainly under hypoxia for both cell lines. The role of MpST could not be addressed as no specific inhibitor is available.

Moreover, ES2 cells showed reduced viability upon the inhibition of both CBS and CSE under hypoxia-mimicked conditions, showing that ES2 cells are especially sensitive to the inhibition of these enzymes in this experimental condition, highlighting their role in hypoxia adaptation and the contribution of cysteine non-oxidative catabolism for cell survival in conditions of hypoxic stress.

\section{Cysteine Degradation Is Necessary to Rescue ATP Production Triggered by xCT Inhibition}

Since results have suggested that cysteine has a role in ATP production under hypoxia-mimicked conditions that can be in part related to $\mathrm{H}_{2} \mathrm{~S}$ synthesis, we investigated if the impact of cysteine on ATP production rely on CBS/CSE-catalyzed $\mathrm{H}_{2} \mathrm{~S}$ production. For that we ascertained if cysteine metabolism was necessary or if a bolus addition of an $\mathrm{H}_{2} \mathrm{~S}$ donor, as NaHS, would be sufficient to counteract the ATP impairment triggered by $\mathrm{xCT}$ inhibition, both at short $(1 \mathrm{~h})$ and long $(48 \mathrm{~h})$ exposure times.

Due to the unstable nature of NaHS that was reported in culture medium (Sun et al., 2017) leading to an instant release of $\mathrm{H}_{2} \mathrm{~S}$ that decays rapidly ( $\mathrm{Hu}$ et al., 2011), we evaluated ATP levels upon NaHS exposure for $1 \mathrm{~h}$ in the experimental conditions tested before. Fu et al. (2012) have reported that in vascular smooth-muscle cells, $1 \mathrm{~h}$ of NaHS exposure was sufficient to alter mitochondrial ATP production under hypoxia in a concentration-dependent manner, consistently with the dual stimulatory/inhibitory nature of $\mathrm{H}_{2} \mathrm{~S}$ for mitochondrial bioenergetics.

In hypoxic ES2 cells, within $1 \mathrm{~h}$ of conditions, while sulfasalazine alone tended to promote a slight increase in ATP (Figure 3A), $30 \mu \mathrm{M}$ NaHS alone led to decreased ATP levels $(p=0.047)$ (Figure 3C), even upon $\mathrm{xCT}$ inhibition (H NaHS vs. $\mathrm{H}$ sulfasalazine $p<0.001 ; \mathrm{H} \mathrm{NaHS}+$ sulfasalazine vs. $\mathrm{H}$ sulfasalazine $p<0.001 ; \mathrm{HC} \mathrm{NaHS}$ vs. $\mathrm{HC}$ sulfasalazine $p=0.002 ; \mathrm{HC} \mathrm{NaHS}+$ sulfasalazine vs. $\mathrm{HC}$ sulfasalazine 
A

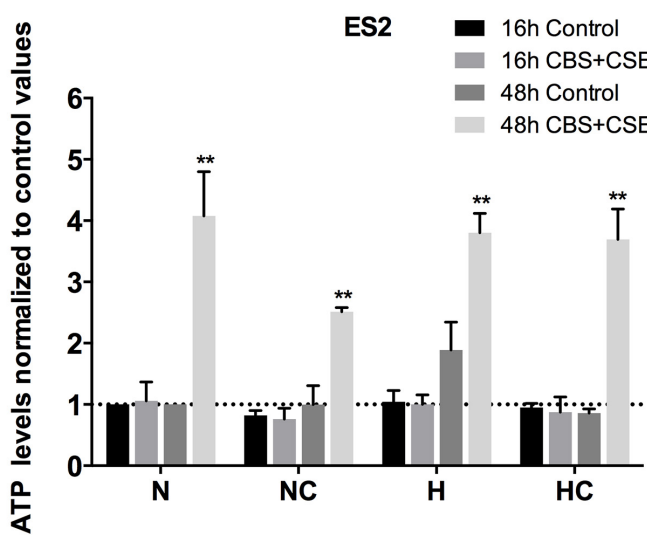

C

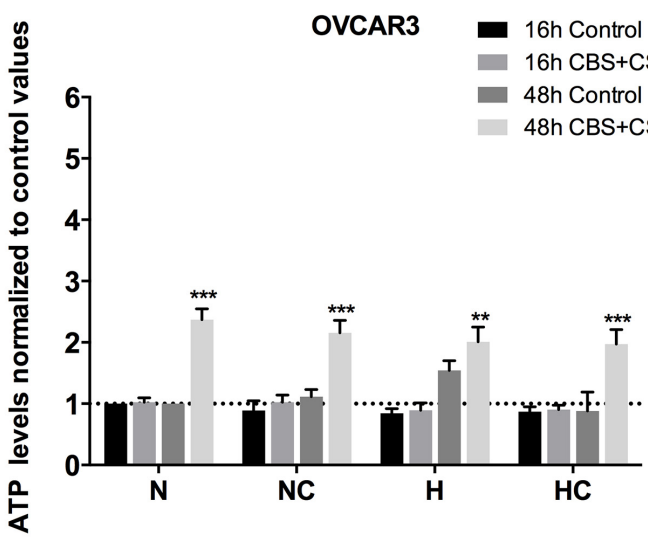

E

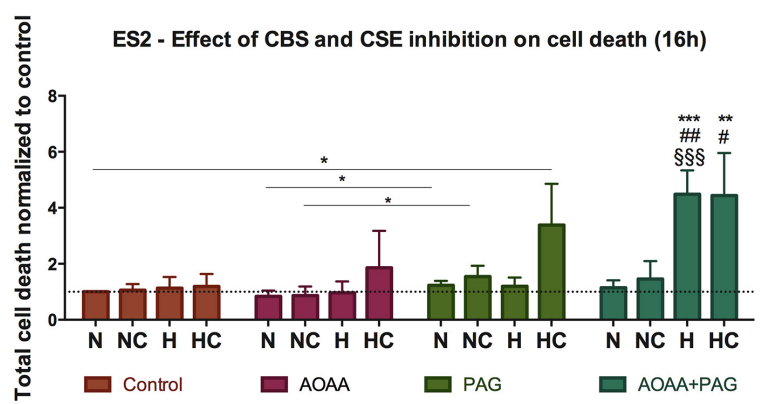

B

ES2 - effect of CBS and CSE inhibition on ATP synthesis

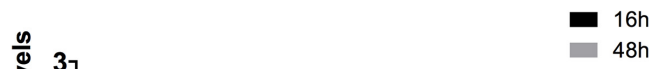

D

OVCAR3 - effect of CBS and CSE inhibition on ATP synthesis

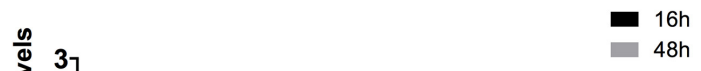

$\mathbf{F}$

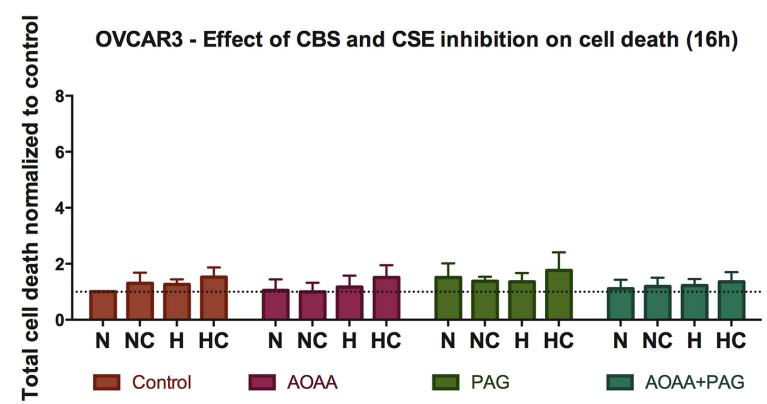

FIGURE 2 | CBS and CSE inhibition does not impair ATP synthesis in ovarian cancer cells but affect ES2 cells survival, mainly in hypoxia-mimicked conditions. (A-D) ATP levels in the presence of $1 \mathrm{mM} \mathrm{AOOA}$ and $3 \mathrm{mM}$ PAG for $16 \mathrm{~h}$ and $48 \mathrm{~h}$ of experimental conditions for ES2 [A - values normalized to control (normoxia without cysteine and without inhibitors) and (B) - values normalized to the respective control and $\log _{2}$ fold change calculation] and OVCAR3 [C - values normalized to control (normoxia without cysteine and without inhibitors) and (D) - values normalized to the respective control and $\log _{2}$ fold change calculation] cells. (A,C) The asterisks $\left(^{*}\right)$ represent the statistical significance compared to the respective control. (B,D) The asterisks $\left(^{*}\right)$ represent the statistical significance compared to N, the section symbols (\$) represents the statistical significance compared to NC and the cardinals (\#) represent statistical significance compared to HC. For ES2, $n=6$ for all treatments for $16 \mathrm{~h}$ of experimental conditions and $n=3$ for $48 \mathrm{~h}$ of experimental conditions. For OVCAR3, $n=6$ for all experimental conditions. (E,F) Cell death levels in the control condition, in the presence of CBS/CSE inhibitor (1 mM AOAA), CSE inhibitor (3 mM PAG) or both inhibitors for ES2 (E) and OVCAR3 (F) cells. The asterisks (*) represent statistical significance between the respective treatments or between AOAA + PAG and its control, the cardinals (\#) represent statistical significance between AOAA + PAG and AOAA alone and the section symbols (§) represent statistical significance between AOAA + PAG and PAG alone. For both cell lines, at least $n=6$ were performed for all experimental conditions. N, normoxia; NC, normoxia with cysteine; $\mathrm{H}$, hypoxia; HC, hypoxia with cysteine. Results are shown as mean \pm SD. ${ }^{*} p<0.05,{ }^{* *} p<0.01,{ }^{* \star *} p<0.001$ [(A,C) independent-samples $t$-test; (B,D-F) one-way ANOVA with post hoc Tukey tests]. 
$p<0.001)$ (Figure 3A). In addition, under hypoxia with cysteine supplementation, NaHS did not affect ATP production (Figure 3C). For OVCAR3 cells, NaHS led to decreased ATP levels both under hypoxia with $(p=0.002)$ and without cysteine $(p=0.003)$ (Figure 3C), but no further differences were observed among treatments (Figure 3B). Furthermore, while $1 \mathrm{~h}$ of sulfasalazine was not sufficient to inhibit ATP levels in ES2 cells, there was a tendency for lower ATP levels in OVCAR3 cells (Figures 3A,B), suggesting that ES2 present higher basal levels of the $\mathrm{xCT}$ transporter or that these cells activate $\mathrm{xCT}$ (or other cysteine transporter) transcription in a more efficient way compared to OVCAR3 cells. In fact, in basal conditions, ES2 cells express higher xCT levels compared to OVCAR3 cells (Supplementary Figure 1B), hence supporting that a more prolonged exposure to sulfasalazine is necessary for the effective blocking of xCT in ES2 cells.

While the $1 \mathrm{~h}$ of experimental conditions is suitable to study NaSH effects, may not allow enough cysteine metabolism to permit relevant $\mathrm{H}_{2} \mathrm{~S}$ production. In fact, with $48 \mathrm{~h}$ of experimental conditions, results have shown that whereas cysteine was able to revert the ATP impairment upon xCT inhibition in both ES2 and OVCAR3 cells $(p<0.001)$, NaHS alone $\left(\mathrm{H}_{2} \mathrm{~S}\right.$ donor) was not, as no differences were found with sulfasalazine with or without NaHS, for both cell lines $(p>0.05)$. These results might indicate that $\mathrm{H}_{2} \mathrm{~S}$ by itself does not rescue ATP production, being cysteine degradation a requirement (Figures 3D,E).

\section{Cysteine Rescues Cellular Metabolism of Hypoxic ES2 Cells}

In order to address the metabolic effects of cysteine supplementation under normoxia and hypoxia in ES2 and OVCAR3 cells, we measured the levels of several metabolites by ${ }^{1} \mathrm{H}-\mathrm{NMR}$ (Figures 4, 5 and Supplementary Figure 2).

The intracellular metabolites were analyzed comparing the effect of cysteine in the metabolic profile of cells cultured in hypoxia with cells cultured in normoxia, in order to determine the variations in organic compounds driven by the presence of cysteine in both environments.

Regarding hypoxic ES2 cells, cysteine increased the intracellular levels of the amino acids alanine $(p=0.009)$, glutamate $(p=0.012)$, glycine $(p=0.008)$ and threonine $(p=0.016)$ (Figure 4A). Cysteine also led to increased intracellular levels of lactate $(p=0.021)$ (Figure 5B), choline $(p=0.005)$ and creatine $(p=0.005)$ (Figure 4C). In the extracellular media (supernatants), $\mathrm{Co}^{2+}$ employed to elicit hypoxia reacted as expected with histidine and therefore precluded any conclusion regarding histidine uptake (Supplementary Figure 2C). Cysteine decreased the release of fumarate under hypoxia ( $p=0.046)$ (Figure 4E).

Through metabolic pathway analysis, results predicted that nine metabolic pathways are significantly and differently altered in ES2 cells by cysteine and hypoxia. The analysis showed alteration in the biosynthetic pathways of: (1) glycine, serine and/threonine; (2) alanine, aspartate and glutamate; (3) glutamine and glutamate; (4) arginine and proline; (5) GSH; (6) primary bile acid; (7) glycerophospholipid; (8) aminoacyl-tRNA; and (9) purine nitrogen bases (Figure 4G).

Regarding OVCAR3 cells, the only significant difference found on the effect of cysteine and hypoxia on intracellular metabolites concentration was on glucose levels, where there was a decrease in the intracellular levels of glucose $(p=0.021)$ (Figure 5). However, cysteine and hypoxia also provided a general tendency for increased intracellular amino acids such as alanine, glutamate, tyrosine and valine (Figure 5A). The measurement of the levels of these amino acids in the cell culture media showed that OVCAR3 cells uptake lower levels of alanine $(p=0.023)$ and proline $(p=0.008)$ and higher levels of glycine $(p=0.013)$ and phenylalanine $(p=0.049)$ due to the exposure to cysteine and hypoxia (Figure 5D). Cysteine and hypoxia also decreased the release of 2-hydroxybutyrate $(p<0.001)$, formate $(p=0.002)$ and isobutyrate $(p<0.001)$ (Figure 5E). As observed in ES2 cells, cysteine seemed to induce the release of glutamine, especially under normoxia (Supplementary Figure 2C).

The metabolite pathway analysis was not performed for OVCAR3 cells because cysteine and hypoxia only altered significantly one metabolite (glucose), thus making this analysis inaccurate.

Importantly, in the absence of cysteine, hypoxia did not alter the intracellular and extracellular levels of glucose and lactate in both cell lines, whereas it led to a decreased uptake of glutamine $(p=0.032)$ and to an increased release of fumarate $(p=0.041)$ in OVCAR3 cells (Supplementary Figure 2D).

\section{Cysteine Supplies Crucial Metabolic Pathways in ES2 Cells, Under Normoxia and Hypoxia}

To clarify the role of cysteine as a carbon source, we followed the metabolites directly derived from cysteine, by using ${ }^{13} \mathrm{C}$-L-cysteine. Our results supported that ES2 cells convert cysteine into lactate (Figures 6A,B). Whereas we observed the presence of satellite resonances indicating double ${ }^{13} \mathrm{C}$-labeled lactate $\left({ }^{13} \mathrm{CH}_{3}{ }^{13} \mathrm{CH}(\mathrm{OH}) \mathrm{COOH}\right)$ in ES2 spectra, these were not observed in OVCAR3 (Figure 6A). The presence of ${ }^{13} \mathrm{C}$ satellite resonances in the lactate is a direct result of ${ }^{13} \mathrm{C}$-L-cysteine conversion into lactate. Furthermore, total (single and doublelabeled) ${ }^{13} \mathrm{C}$-lactate and the percentage of double-labeled ${ }^{13} \mathrm{C}$ lactate tended to be higher under normoxia $\left(\mathrm{NC}{ }^{13} \mathrm{C}\right.$ and $\mathrm{NC}$ double ${ }^{13} \mathrm{C}$, respectively) compared to hypoxia ( $\mathrm{HC}{ }^{13} \mathrm{C}$ and $\mathrm{HC}$ double ${ }^{13} \mathrm{C}$, respectively) (Figure 6B). We also observed that ES2 cells tended to consume glucose faster than OVCAR3 cells both under normoxia and hypoxia in the presence of cysteine (Figure 6C).

Furthermore, our results indicated that ES2 cells convert cysteine mainly in GSH (GSH-CYS), lactate (Lac-3) and acetylCoA (A-CoA). Small amounts of alanine (Ala3) and glutamate (Glu4) and of other two unidentified compounds (Unk1 and Unk2) were also detected (Figure 6D).

Finally, under normoxia, ES2 cells (ES2 NC) presented cysteine in solution instead of cystine, and produced different unknown compounds, while under hypoxia (ES2 HC) the main compound presented was cystine. In the case of OVCAR3 
A

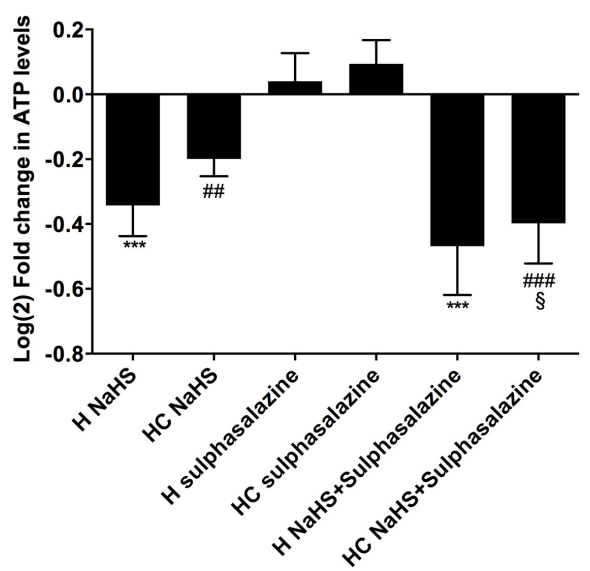

B

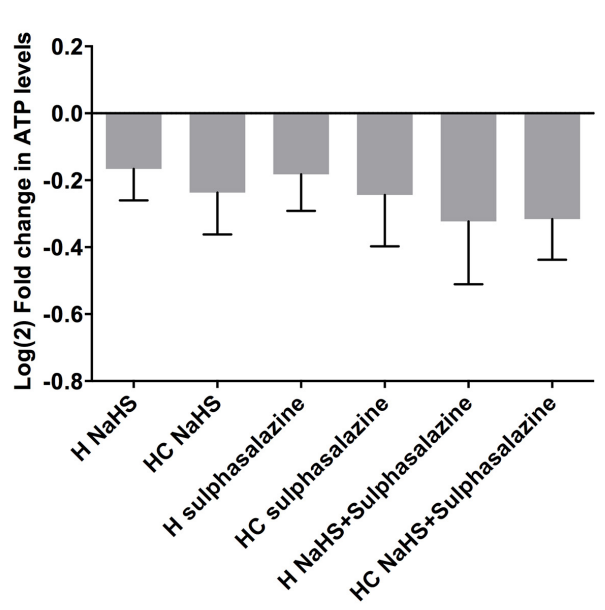

C

ES2 and OVCAR3 - $1 \mathrm{~h}$ experimental conditions

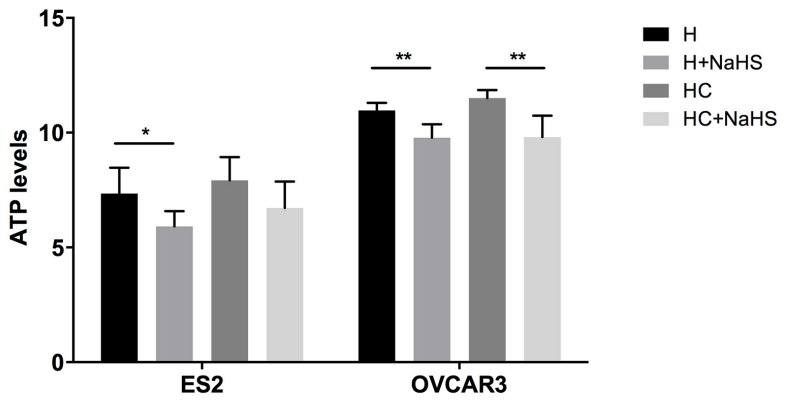

D

ES2 - 48 h experimental conditions

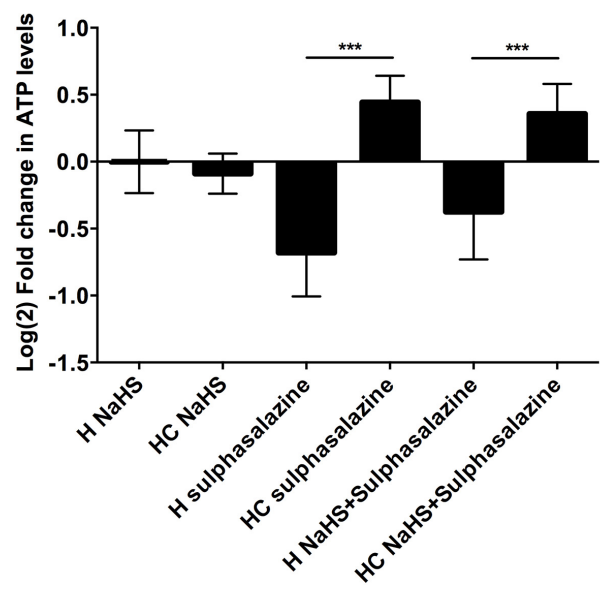

E

OVCAR3 - 48 h experimental conditions

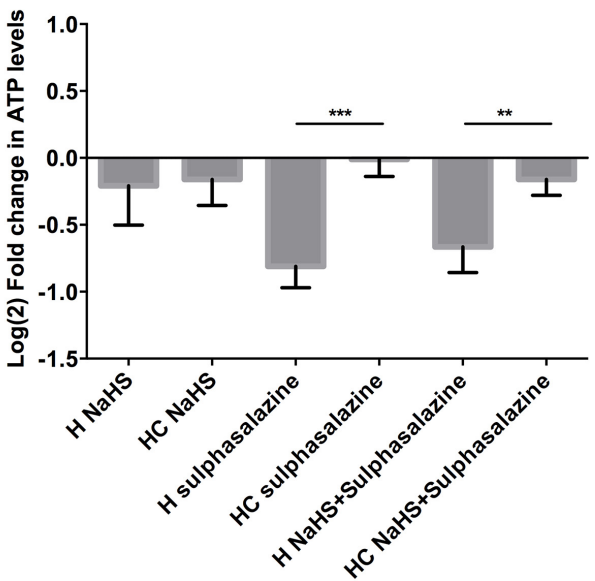

FIGURE 3 | Cysteine, but not NaHS, is able to rescue the ATP synthesis impairment, after $48 \mathrm{~h}$ under hypoxia triggered by $\mathrm{xCT}$ inhibition. (A-C) ATP levels for $1 \mathrm{~h}$ of experimental conditions for (C). ES2 and OVCAR3 cells under hypoxia with and without cysteine and in the presence of the H2S donor, NaHS sulfasalazine in which $n=5$ for ES2; and $\mathrm{H}$ sulfasalazine and H NaHS C sulfasalazine, in which $n=5$ for OVCAR3. (D,E) ATP levels for $48 \mathrm{~h}$ of experimental (un-normalized data), and (D) ES2 and (E) OVCAR3 cells under hypoxia with and without cysteine supplementation and in the presence of the xCT inhibitor, conditions for (A) ES2 and (B) OVCAR3 cells under hypoxia with and without cysteine and in the presence of the XCT inhibitor, sulfasalazine and the H2S donor, NaHS. Data were normalized to the respective control condition (the same environmental condition $\mathrm{H} / \mathrm{HC}$ without $\mathrm{NaHS}$ or sulfasalazine). Data are presented as log2 fold change

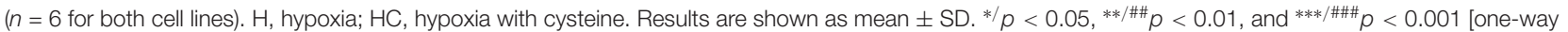
ANOVA with post hoc Tukey tests for (A,B,D,E) and independent-samples $t$-test for (C)]. 

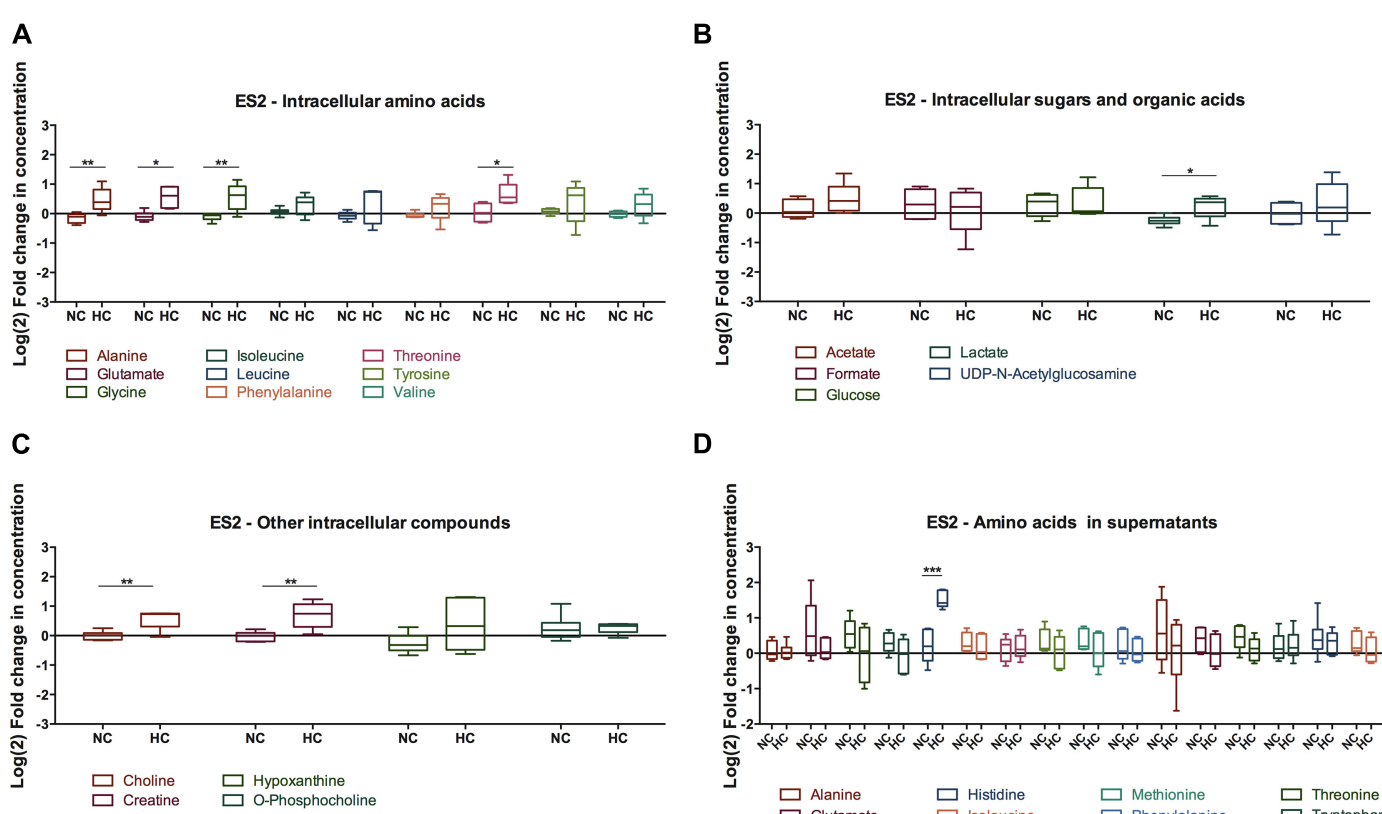

D
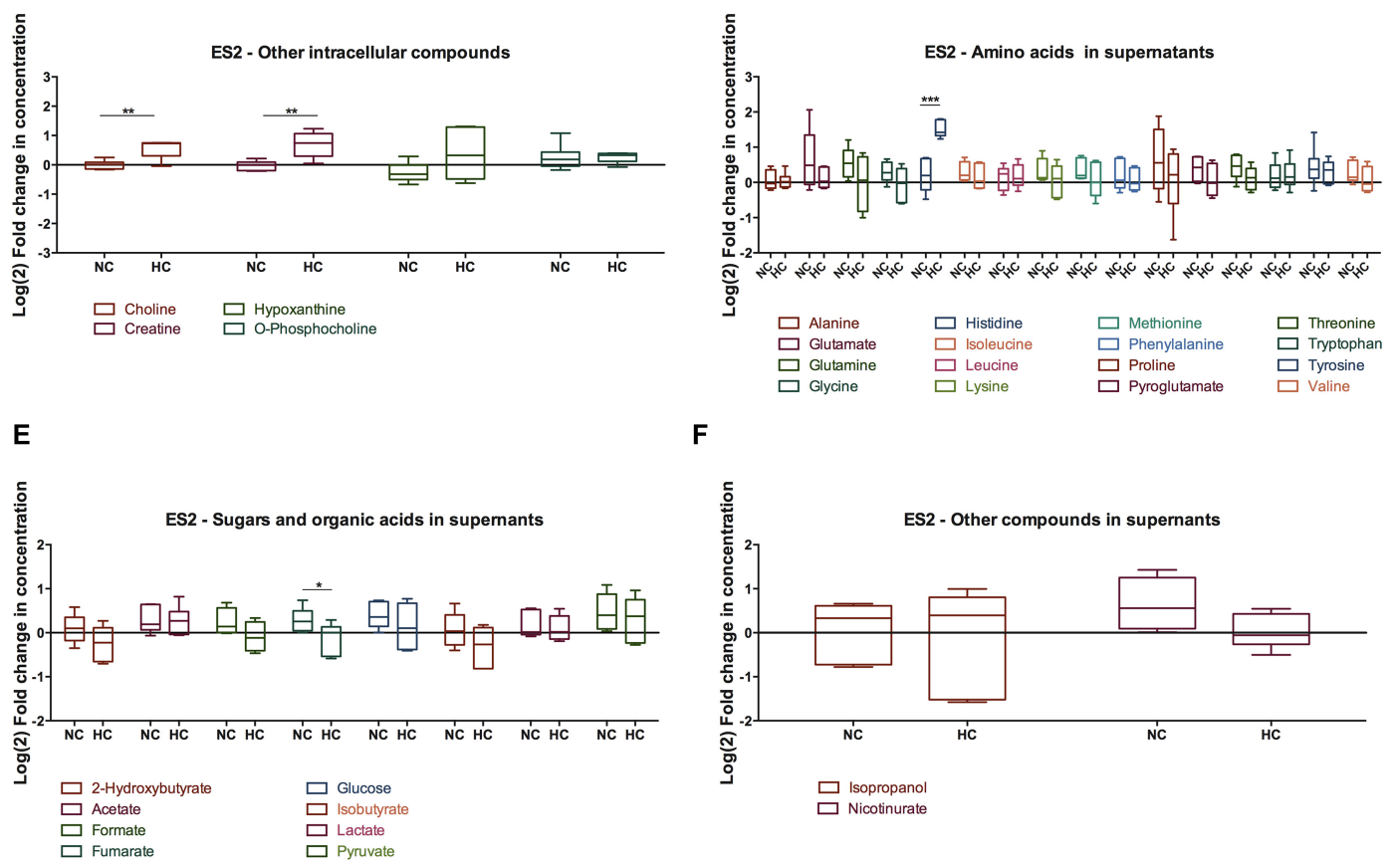

$\mathbf{F}$
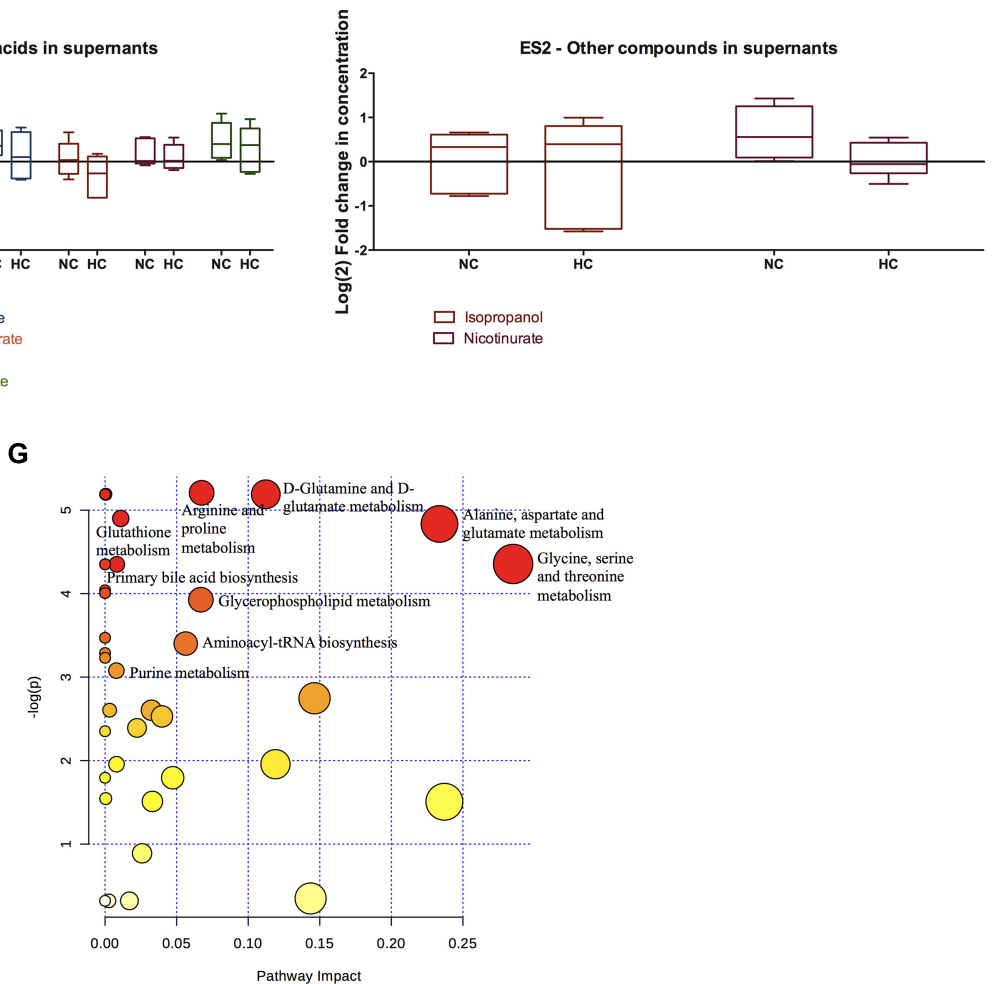

FIGURE 4 | Cysteine rescues ES2 cellular metabolism and impacts several metabolic pathways under hypoxia. (A-F) Metabolites levels for $48 \mathrm{~h}$ of experimental conditions for ES2 cells. (A) Intracellular amino acids; (B) intracellular sugars and organic acids; (C) other intracellular metabolites; (D) amino acids in supernatants; (E) sugars and organic acids in supernatants; $(\mathbf{F})$ other metabolites in supernatants. Data were normalized to the respective control condition (the same environmental condition $\mathrm{NC} / \mathrm{N}$ and $\mathrm{HC} / \mathrm{H}$ ). $\mathrm{NC}$, normoxia with cysteine; $\mathrm{HC}$, hypoxia with cysteine. Results are shown as median with 25 th to 75 th percentiles. ${ }^{*} p<0.05,{ }^{* \star} p<0.01,{ }^{* \star *} p<0.001$ (independent-samples $t$-test: NC, $n=6$; $\mathrm{HC}, n=5$ ). (G) Metabolic pathway analysis for the effect of cysteine under normoxia and hypoxia in intracellular ES2 metabolites. All the matched pathways are displayed as circles. The color and size of each circle are based on $p$-value and pathway impact value, respectively. The most impacted pathways having statistical significance $(p<0.05)$ are indicated. Source: https://www.metaboanalyst.ca/Metabo Analyst/faces/home.xhtml. 

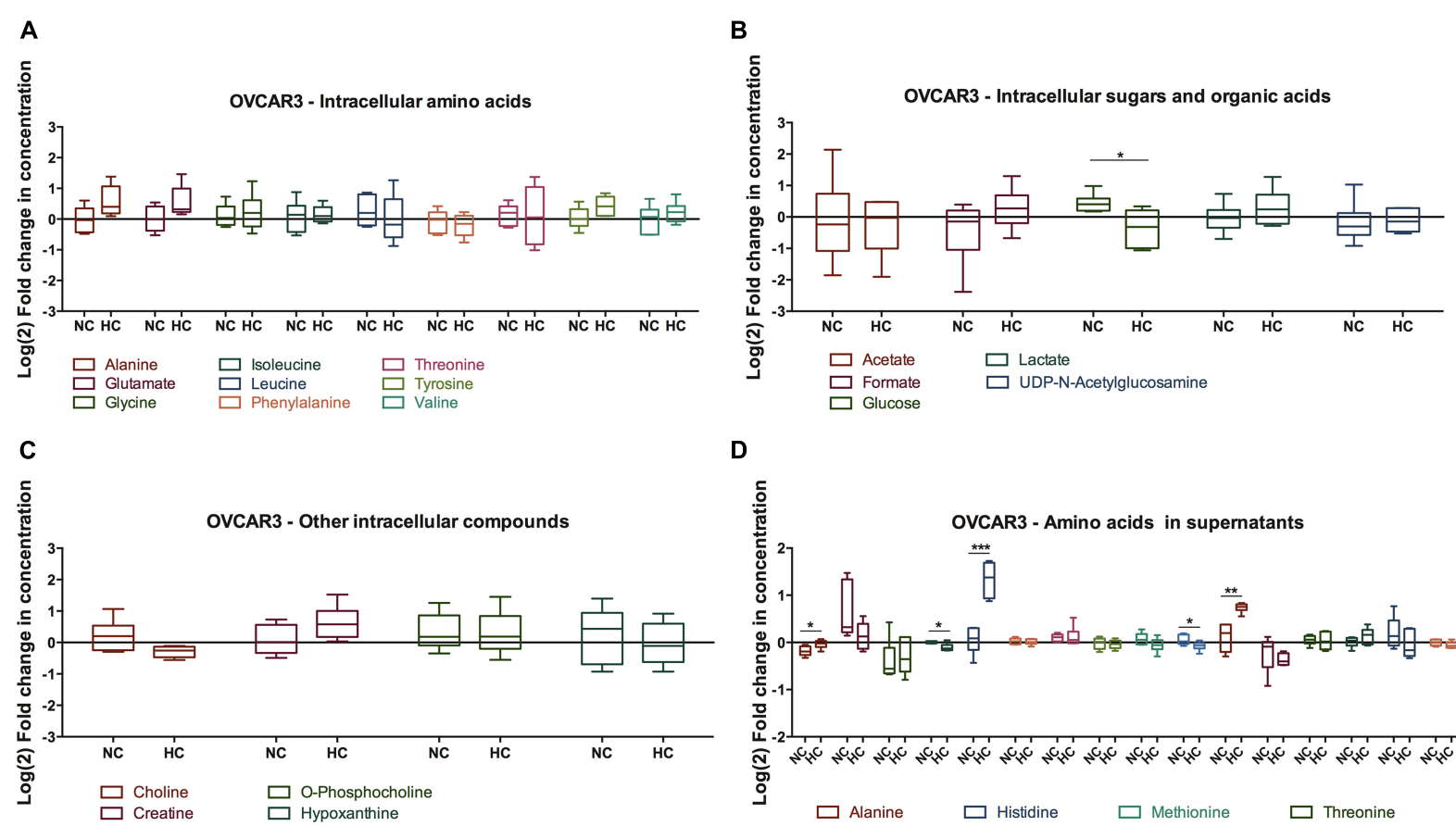

D
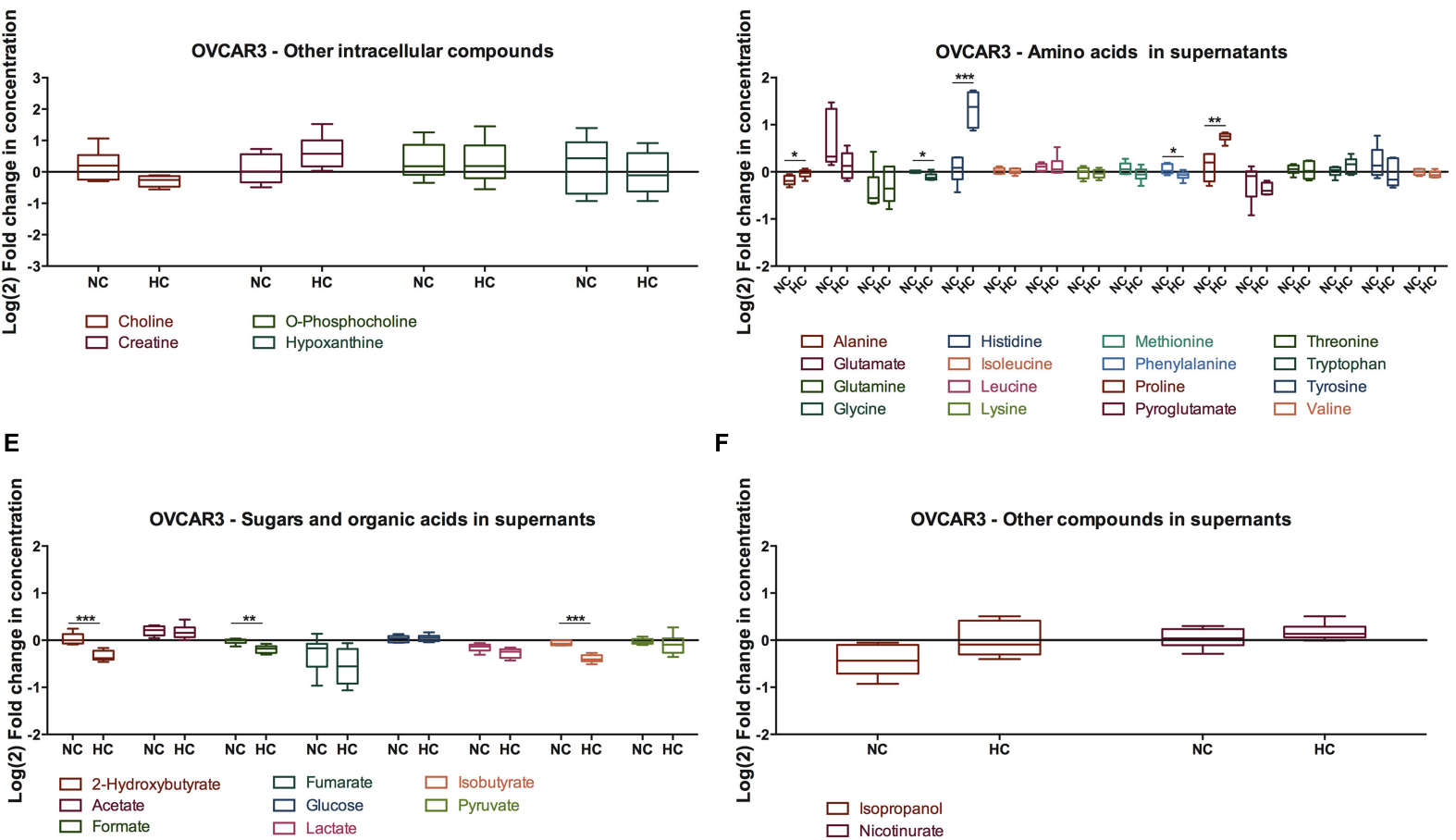

$\mathbf{F}$

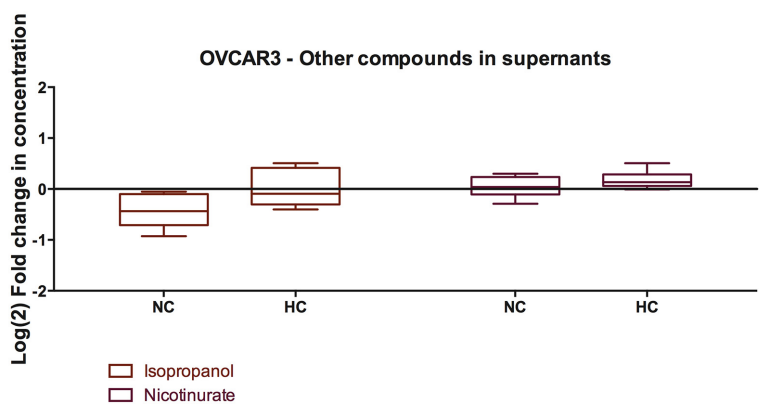

FIGURE 5 | Effect of cysteine in OVCAR3 metabolites under normoxia and hypoxia. Metabolites levels for $48 \mathrm{~h}$ of experimental conditions for OVCAR3 cells. (A) Intracellular amino acids; (B) intracellular sugars and organic acids; (C) other intracellular metabolites; (D) amino acids in supernatants; (E) sugars and organic acids in supernatants; (F) other metabolites in supernatants. Data were normalized to the respective control condition (the same environmental condition NC/N and $\mathrm{HC} / \mathrm{H})$. NC, normoxia with cysteine; HC, hypoxia with cysteine. Results are shown as median with 25th to 75th percentiles. ${ }^{*} p<0.05,{ }^{* \star} p<0.01$, ${ }^{* \star *} p<0.001$ (independent-samples $t$-test: NC, $n=6$; $\mathrm{HC}, n=6$ ).

cells the profile was similar both under normoxia (OVCAR3 $\mathrm{NC}$ ) and hypoxia (OVCAR3 HC), with cystine being the most representative compound (Figure 6E).

\section{DISCUSSION}

In this work, we provide novel data supporting that cysteine promotes sulfur and carbon metabolism reprogramming, underlying the adaptation to hypoxic microenvironment in ovarian cancer cells.

As a solid tumor grows, cancer cells are exposed to regions of hypoxia, long established as a stimulus for tumor progression and resistance to therapy (Vaupel and Mayer, 2007; Semenza, 2012).
We have recently proposed that cysteine allows adaptation to hypoxic environments and also contributes to escape from carboplatin-induced death in ovarian cancer cells (Nunes et al., 2018a,b). In here, we aimed to investigate the mechanisms by which cysteine protects ovarian cancer cells under hypoxia, by addressing its role in cellular metabolism, namely through energy production.

Uptake of cystine, the oxidized form of cysteine, is mediated by xCT (solute carrier family 7 member 11 - SLC7A11), a member of the cystine-glutamate transporter xc' system (Sato et al., 2000). Intracellularly, cystine is reduced to cysteine, which is the ratelimiting substrate for GSH synthesis, making xCT pivotal in the cellular redox balance maintenance (reviewed in Conrad and Sato, 2012). Herein, we have shown mitochondrial localization of 


\section{A}

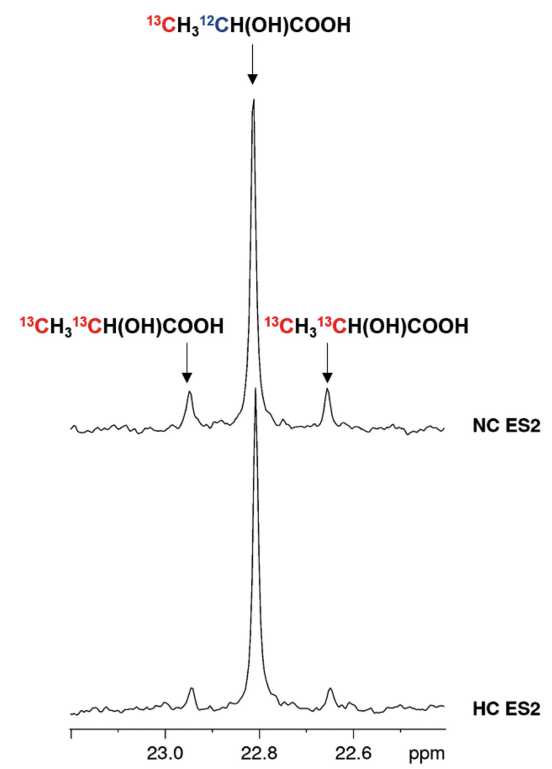

B

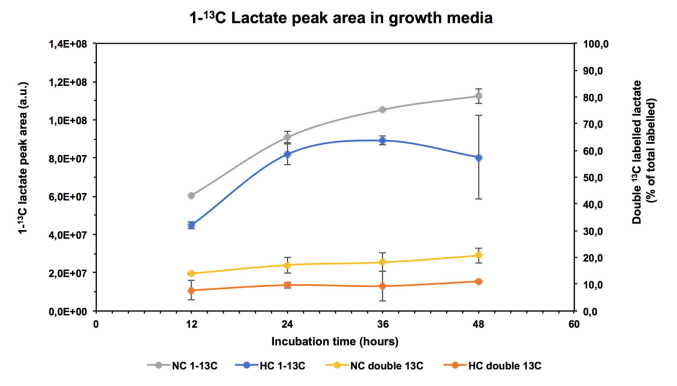

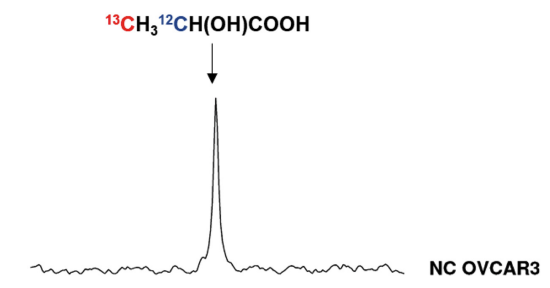

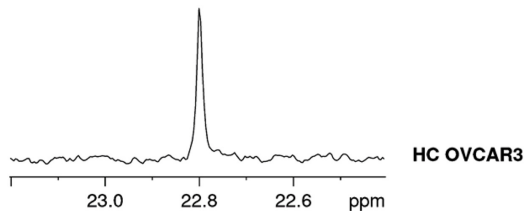

C

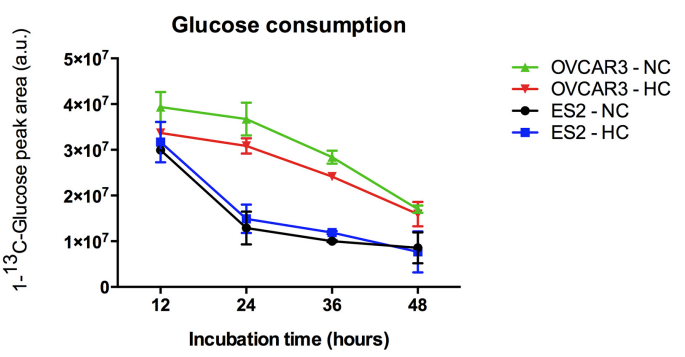

D

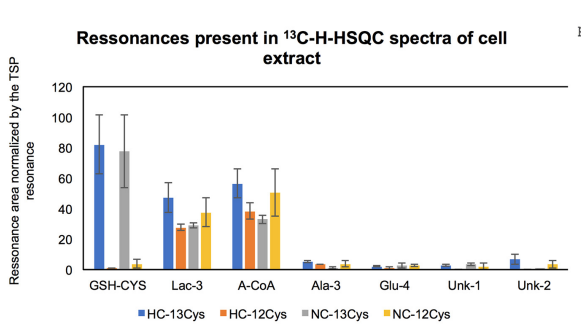

E
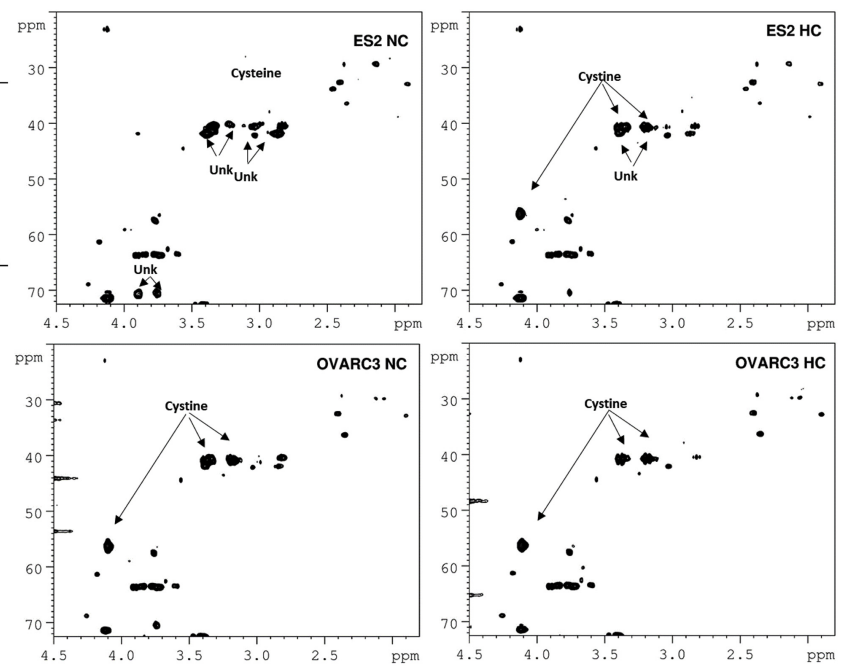

FIGURE 6 | Cysteine is directly used by ES2 cells in the main metabolic pathways. (A) Highlight of the lactate methyl group resonance on the ${ }^{13} \mathrm{C}-\mathrm{NMR}$ spectra of $48 \mathrm{~h}$ culture media incubated with $\mathrm{U}-{ }^{13} \mathrm{C}$-cysteine. On the left panel, ES2 cells under normoxia (upper spectra) and under hypoxia (lower spectra); on the right panel, OVCAR3 cells under normoxia (upper spectra) and under hypoxia (lower spectra). (B) Production of lactate by ES2 cells in culture media at different time points (12, 24, 36, and 48 h). (C) Glucose consumption in ES2 and OVCAR3 cells. (D) Resonances areas of the ${ }^{13} \mathrm{C}-1 \mathrm{H}-\mathrm{HSQC}$ projection on ${ }^{13} \mathrm{C}$ spectra normalized by TSP area in the cell extracts. (E) Highlight of ${ }^{13} \mathrm{C}-1 \mathrm{H}-\mathrm{HSQC}$ spectra of the growth media at $48 \mathrm{~h}$ incubation in the presence of $\mathrm{U}-{ }^{13} \mathrm{C}$-cysteine under normoxia and hypoxia conditions. NC, normoxia with cysteine; HC, hypoxia with cysteine. (B-D) Results are shown as mean \pm SD. Assays were performed in biological triplicates. 
the $\mathrm{xCT}$ transporter concomitant with impaired ATP production triggered by its pharmacological inhibition under hypoxia, thus indicating a role of the $\mathrm{xc}^{-}$system via cystine uptake also in energy production. These data are in accordance with recent findings supporting a role of Nrf2 in the regulation of mitochondrial ATP synthesis (reviewed in Vomund et al., 2017). As a transcription factor, Nrf2 was already reported to regulate the expression of $\mathrm{xCT}$ and the activity of the $\mathrm{xc}^{-}$system in response to oxidative stress in human breast cancer cells (Habib et al., 2015).

Cysteine's role in mitochondrial ATP synthesis might be associated to its non-oxidative metabolism resulting in $\mathrm{H}_{2} \mathrm{~S}$ (via CBS, CSE or MpST) and/or CysSSH (via CARS2) release. $\mathrm{H}_{2} \mathrm{~S}$ is the only inorganic compound presenting a bioenergetic role in mammalian cells' mitochondria (Goubern et al., 2007), that was already reported to contribute to mitochondrial ATP production through the activity of the enzymes involved in cysteine metabolism: MpST in conjunction with CAT (Módis et al., 2013a,b; Abdollahi Govar et al., 2020; Augsburger et al., 2020), CSE (Fu et al., 2012), and CBS (Bhattacharyya et al., 2013; Szabo et al., 2013). At low concentrations (nM), $\mathrm{H}_{2} \mathrm{~S}$ is known to stimulate mitochondrial bioenergetics by way of different mechanisms: through donation of electron equivalents to the quinol pool via sulfide:quinone oxidoreductase (SQR); by the glycolytic enzyme glyceraldehyde 3-phosphate dehydrogenase activation, and by persulfidation of ATP synthase (reviewed in Giuffrè and Vicente, 2018). In addition, Li and Yang (2015) reported a role of $\mathrm{CSE} / \mathrm{H}_{2} \mathrm{~S}$ system in enhancing mtDNA replication and cellular bioenergetics both in smooth muscle cells and mouse aorta tissues. In fact, this can be an explanation for the increased number of mitochondria in ES2 cells under hypoxia, as the mitochondrial marker/endogenous control TOMM20 is overexpressed. More recently, Chakraborty et al. (2018) reported a new role of CBS in the regulation of mitochondria morphogenesis, promoting tumor progression in ovarian cancer. Specifically under hypoxia conditions, $\mathrm{H}_{2} \mathrm{~S}$ was reported to decrease reactive oxygen species (ROS), mediated by CBS mitochondrial accumulation (Teng et al., 2013) and induce ATP production, mediated by CSE translocation into the mitochondria (Fu et al., 2012). A different adaptive strategy to hypoxia has been reported by Malagrinò et al. (2019) for the colorectal cancer cell line SW480, which exhibited a lower mitochondrial mass in response to hypoxia, although the mitochondria were enriched in $\mathrm{H}_{2} \mathrm{~S}$-disposal capacity via increased mitochondrial SQR expression. This increased mitochondrial SQR renders hypoxic SW480 cells more equipped to inject $\mathrm{H}_{2} \mathrm{~S}$-derived electron equivalents into the mitochondrial electron transfer chain and sustain mitochondrial bioenergetics.

In our study, short (2-16 h) exposure to CBS and CSE inhibitors did not afford significant differences in ATP levels in both cell lines, with the exception of OVCAR3 cells at $2 \mathrm{~h}$ under hypoxia with cysteine supplementation in which the inhibitors led to decreased ATP levels (Supplementary Figure 3A). Hence, OVCAR3 cells, under hypoxia, may channel the extra cysteine to degradation, thereby producing $\mathrm{H}_{2} \mathrm{~S}$ and/or $\mathrm{CysSSH}$, and enhancing ATP production. Despite the absent effects at shorter times, the observed increased ATP levels at prolonged $(48 \mathrm{~h}$ ) exposure to CBS and CSE inhibitors indicates that the inhibition of both enzymes allows for compensatory or alternative mechanisms of energy production, probably including CAT/MpST and/or CARS2 activity. Given the fact that both CBS and CSE have been reported to partially relocate to mitochondria in hypoxia (Fu et al., 2012; Teng et al., 2013), available cysteine may be converted in the mitochondria to $\mathrm{H}_{2} \mathrm{~S}$ by CBS, CSE and MpST, or to CysSSH by CARS2. Additionally, cystine can be converted to CysSSH and pyruvate by CBS and CSE. Therefore, whereas excess cysteine may trigger over-production of $\mathrm{H}_{2} \mathrm{~S}$ and/or CysSSH via CBS and CSE to the point they inhibit the mitochondrial electron transfer chain and thereby impair ATP production, in the presence of their inhibitors AOAA and PAG, this inhibitory effect is likely released and 'safer' cysteinedegradation mechanisms can be deployed, linked to stimulation of ATP production.

Under hypoxia we did not observe differences in MpST protein levels in both cell lines (Supplementary Figure 3B), although we observed a mitochondrial MpST enrichment compared to the cytosolic content (Supplementary Figure 3C). Given that cysteine is a poor co-substrate for MpST as sulfane sulfur acceptor to generate CysSSH with respect to other possible co-substrates such as thioredoxin, the excess cysteine load imposed on hypoxic cells may push the CAT/MpST system into higher - yet controlled - CysSSH/ $\mathrm{H}_{2} \mathrm{~S}$ production. Interestingly, enzymatic studies performed in E. coli showed that a bacterial MpST homolog abrogates oxidative stress via L-cysteine (Mironov et al., 2017). Another hypothesis is that diversion of cysteine for CARS2-mediated generation of CysSSH affords a protective role from cysteine oxidation in oxidative stress triggered by hypoxic conditions, as recently shown by Zivanovic et al. (2019) regarding the cysteine persulfidation prevention of protein cysteine oxidative damage.

Considering the relevance of cysteine in ATP production, our results showed that cysteine metabolism may operate in a more intricate manner than simply increased $\mathrm{H}_{2} \mathrm{~S}$ production and concurrent ATP production. Although some studies showed that $\mathrm{NaHS}$, an exogenous $\mathrm{H}_{2} \mathrm{~S}$ source, was sufficient to increase mitochondrial ATP production under hypoxia (Fu et al., 2012), our results showed that $\mathrm{H}_{2} \mathrm{~S}$ per se was not sufficient to counteract the impaired ATP production driven by sulfasalazine $(\mathrm{xCT}$ inhibitor), under hypoxia in both ES2 and OVCAR3 cells. Therefore, our experiments support that cysteine metabolism, dependent on $\mathrm{xCT}$ transporter, provides alternative sources for energy production in ovarian cancer cells (Figure 7A).

The synthesis of GSH is another way of cysteine contributing for ATP production. The incorporation of extra cysteine in GSH allows cells to escape from oxidative stress and enables increased cell viability and proliferation, therefore leading to increased ATP synthesis. In fact, our previous data have supported a role of a higher thiols turnover in hypoxia adaptation, especially in ES2 cells (Nunes et al., 2018b). Interestingly, $\mathrm{H}_{2} \mathrm{~S}$ was also reported to increase the production of GSH by inducing the expression of cystine/cysteine transporters and by redistributing GSH to mitochondria in mouse neuronal cell models (Kimura et al., 2010).

Despite the fact that in addition to $\mathrm{H}_{2} \mathrm{~S}$ and CysSSH production, cysteine and cystine catabolism generate pyruvate 

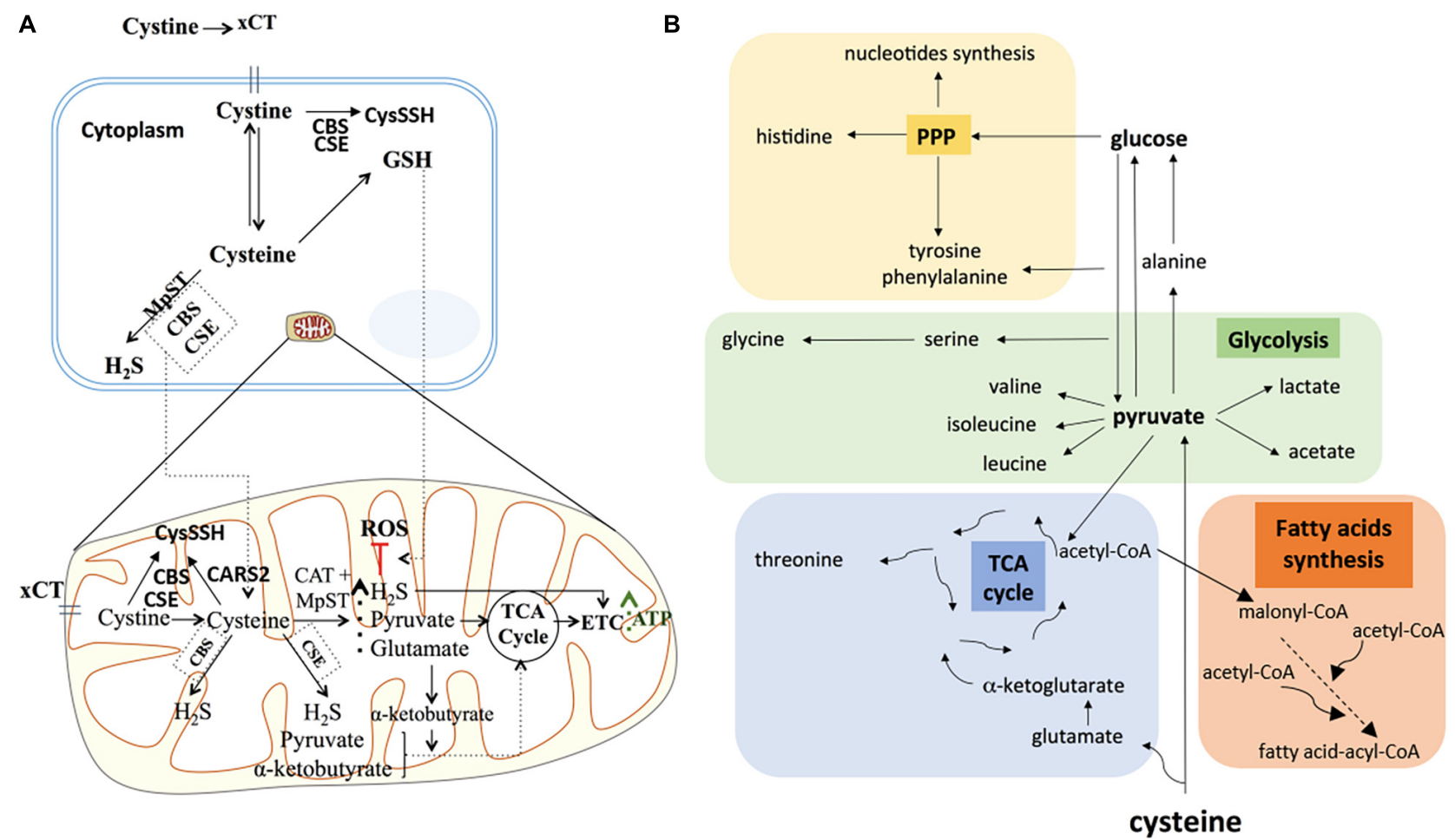

FIGURE 7 | Cysteine possible direct and indirect roles in ATP synthesis and in carbon metabolism reprogramming under hypoxia in ovarian cancer cells. (A) Under hypoxia, cysteine degradation could contribute directly to ATP production via not only $\mathrm{H}_{2} \mathrm{~S}$ generation, but also via pyruvate and $\alpha$-ketobutyrate that could further supply the TCA cycle, leading to increased ATP synthesis. Cysteine could also present an indirect role in ATP synthesis mediated by increasing GSH content under hypoxia, hence counteracting oxidative stress and thereby increasing cellular metabolism. Cystine can also be converted into cysteine persulfide (CysSSH) by CSE and CBS in the cytoplasm or by CSE, CBS and CARS2 in the mitochondria. (B) The axis cysteine-pyruvate-glucose is central in whole metabolic network of carbon. Cysteine degradation can originate pyruvate and glutamate. Pyruvate besides being a major supplier of tricarboxylic acids (TCA) cycle, it can be converted into valine, isoleucine, leucine, alanine, lactate, and acetate. Alanine can be a source of glucose through gluconeogenesis. Glycolysis produce intermediates to supply the TCA cycle (a hub for many precursors of organic compounds, such as threonine) and the pentose phosphate pathway (PPP). PPP intermediates can be converted into amino acids such as histidine and can be conjugated with glycolysis intermediates, originating tyrosine, phenylalanine and serine, which can be converted into glycine. PPP is also crucial in the nucleotide's synthesis. Acetyl-CoA is a central organic compound in metabolism, when cysteine-derived it proves that cysteine is a valuable supplier of TCA cycle and amino acids and fatty acids syntheses. The increased concentration of these compounds under hypoxia, suggests that cysteine is pushing the metabolic flow in order to supply the main carbon metabolic pathways. The direct incorporation of cysteine into these compounds is possible, however, further studies are needed to clarify this. Based on information from www.bioinfo.org.cn.

as well (Wang, 2012; Bonifácio et al., 2020), cysteine is not commonly considered as a carbon source. Herein, we showed that cysteine gives rise to lactate by being firstly converted into pyruvate and alanine, indicating that cysteine could also be used in gluconeogenesis (Figure 7B). Most importantly, cysteine also originates acetyl-CoA, which is a central metabolite, supplying the TCA cycle, fatty acids synthesis and amino acids synthesis. Our study reinforces that cysteine can account for biosynthesis and bioenergetics not only as a sulfur source but also as a carbon donor.

Importantly, Beaufort et al. (2014) characterized 39 ovarian cancer cell lines in order to correlate the cellular and molecular features with their tumorigenic phenotype. In that study, ES2, but not OVCAR3, was included in the most aggressive subset of ovarian cancer cells (Beaufort et al., 2014). In here, our data supported that cysteine orchestration in metabolic remodeling and plasticity can be a crucial phenomenon for more aggressive cancer cells phenotype. Strikingly, ${ }^{1} \mathrm{H}-\mathrm{NMR}$ results showed that the metabolic impact of cysteine under hypoxia was much more pronounced in ES2 cells than in OVCAR3 cells, translated by the remarkable number of metabolic pathways that were significantly altered. Therefore, taken together, our results reinforced the role of cysteine as a valuable carbon source, from which cancer cells take advantage on the course of the metabolic rewiring they undergo under hypoxia. In particular, cysteine is a central carbon source for ES2 cells, supporting their redox capacity by supplying GSH synthesis and allowing the maintenance of pivotal biosynthetic and bioenergetic pathways dependent on acetyl-CoA. Furthermore, results suggested that under hypoxia, cysteine allowed to increase the rate of some metabolic pathways in ES2 cells, as increased intracellular levels of several amino acids and other compounds were observed. Regarding OVCAR3 cells, results supported that cysteine impacts differently the 
cellular needs of amino acids under normoxia and hypoxia. Moreover, when comparing to OVCAR3, results suggest that ES2 cells are better adapted to hypoxia and to the use of cysteine to overcome the hypoxic stress, as seen by the higher number of metabolic pathways that were significantly altered by cysteine under hypoxia.

Interestingly, while cysteine was able to rescue the impaired ATP synthesis triggered by xCT inhibition, it was not able to increase ATP synthesis upon $\beta$-oxidation and glycolysis inhibition (Supplementary Figure 3D), indicating that cysteine is not enough to replace the contribution of these pathways for ATP production.

Together, the results support that ES2 and OVCAR3 cells use cysteine differently in order to cope with hypoxia, where cysteine especially impacts hypoxic ES2 cells metabolic features, enhancing the metabolic reprogramming. In Figure 7, we present the possible direct and indirect pathways in which cysteine can be a metabolic coin, promoting ATP production in hypoxic ovarian cancer cells. The profound metabolic impact that cysteine showed under hypoxia in ES2 cells suggests a strong remodeling of the carbon metabolism.

This work lights again that disturbing cysteine metabolic network can be a promising tool not only in ovarian cancer but also in all cancer models that rely their survival on cysteine bioavailability and metabolic versatility.

\section{DATA AVAILABILITY STATEMENT}

The original contributions presented in the study are included in the article/Supplementary Material, further inquiries can be directed to the corresponding author.

\section{REFERENCES}

Abdollahi Govar, A., Törő, G., Szaniszlo, P., Pavlidou, A., Bibli, S.-I., Thanki, K., et al. (2020). 3-Mercaptopyruvate sulfurtransferase supports endothelial cell angiogenesis and bioenergetics. Br. J. Pharmacol. 177, 866-883. doi: 10.1111/ bph. 14574

Akaike, T., Ida, T., Wei, F. Y., Nishida, M., Kumagai, Y., Alam, M. M., et al. (2017). Cysteinyl-tRNA synthetase governs cysteine polysulfidation and mitochondrial bioenergetics. Nat. Commun. 8:1177. doi: 10.1038/s41467-01701311-y

Augsburger, F., Randi, E. B., Jendly, M., Ascencao, K., Dilek, N., and Szabo, C. (2020). Role of 3-mercaptopyruvate sulfurtransferase in the regulation of proliferation, migration, and bioenergetics in murine colon cancer cells. Biomolecules 10:447. doi: 10.3390/biom10030447

Balendiran, G. K., Dabur, R., and Fraser, D. (2004). The role of glutathione in cancer. Cell Biochem. Funct. 22, 343-352. doi: 10.1002/cbf.1149

Bast, R. C. Jr., Hennessy, B., and Mills, G. B. (2009). The biology of ovarian cancer: new opportunities for translation. Nat. Rev. Cancer 9, 415-428. doi: $10.1038 / \mathrm{nrc} 2644$

Beaufort, C. M., Helmijr, J. C. A., Piskorz, A. M., Hoogstraat, M., Ruigrok-Ritstier, K., Besselink, N., et al. (2014). Ovarian cancer cell line panel (OCCP): clinical importance of in vitro morphological subtypes. PLoS One 9:e103988. doi: 10. 1371/journal.pone. 0103988

Bhattacharyya, S., Saha, S., Giri, K. I, Lanza, R., Nair, K. S., Jennings, N. B., et al. (2013). Cystathionine beta-synthase (CBS) contributes to advanced ovarian

\section{AUTHOR CONTRIBUTIONS}

SN planned and performed most experiments. CR, IS, and FS performed experimental assays. JV coordinated $\mathrm{H} 2 \mathrm{~S}$ experiments. SP coordinated the pharmacological assays. AF participated in the pathophysiological contextualization of the study. LG coordinated NMR spectroscopy analyses. JS coordinated the whole research project and ensured the funding. $\mathrm{CM}$ performed the experiments and contributed for the revised version of the manuscript, which ended up being accepted for publication. All the authors read, discussed, and approved the final version of the manuscript.

\section{FUNDING}

This research was supported by Fundação para a Ciência e Tecnologia (FCT) (Ph.D. ProRegeM program, Ref: $\mathrm{PD} / \mathrm{BD} / 105893 / 2014 ; \quad \mathrm{FCT}$ individual Ph.D. fellowship Ref: 2020.06956.BD) and iNOVA4 Health (Project 4 and Project 21). iNOVA4Health-UID/Multi/04462/2013 is a program financially supported by Fundação para a Ciência e Tecnologia/ Ministério da Educação e Ciência, through national funds. The authors would like to acknowledge the Instituto Português de Oncologia de Lisboa Francisco Gentil (IPOLFG) for partially funding the project.

\section{SUPPLEMENTARY MATERIAL}

The Supplementary Material for this article can be found online at: https://www.frontiersin.org/articles/10.3389/fcell.2021. 722412/full\#supplementary-material

cancer progression and drug resistance. PLoS One 8:e79167. doi: 10.1371/ journal.pone.0079167

Bianco, C. L., Akaike, T., Ida, T., Nagy, P., Bogdandi, V., Toscano, J. P., et al. (2019). The reaction of hydrogen sulfide with disulfides: formation of a stable trisulfide and implications for biological systems. Br. J. Pharmacol. 176, 671-683. doi: 10.1111/bph.14372

Bonifácio, V. D. B., Pereira, S. A., Serpa, J., and Vicente, J. B. (2020). Cysteine metabolic circuitries: druggable targets in cancer. Br. J. Cancer 124, 862-879. doi: 10.1038/s41416-020-01156-1

Chakraborty, P. K., Murphy, B., Mustafi, S. B., Dey, A., Xiong, X., Rao, G., et al. (2018). Cystathionine $\beta$-synthase regulates mitochondrial morphogenesis in ovarian cancer. FASEB J. 32, 4145-4157. doi: 10.1096/fj.201701095R

Conrad, M., and Sato, H. (2012). The oxidative stress-inducible cystine/glutamate antiporter, system xc-: cystine supplier and beyond. Amino Acids 42, 231-246. doi: 10.1007/s00726-011-0867-5

Cooke, S. L., Brenton, J. D., and Way, R. (2011). Evolution of platinum resistance in high-grade serous ovarian cancer. Lancet Oncol. 12, 1169-1174. doi: 10.1016/ S1470-2045(11)70123-1

Desai, A., Xu, J., Aysola, K., Qin, Y., Okoli, C., Hariprasad, R., et al. (2014). Epithelial ovarian cancer: an overview. World J. Transl. Med. 3, 10-29. doi: 10.5528/wjtm.v3.i1.1.Epithelial

Ferlay, J., Soerjomataram, I., Ervik, M., Dikshit, R., Eser, S., Mathers, C., et al. (2013). GLOBOCAN 2012 v1.0, cancer incidence and mortality worldwide: IARC cancerbase no. 11. Lyon. Int J Cancer 144, 1941-1953. doi: 10.1002/ijc. 31937 
Filipovic, M. R., Zivanovic, J., Alvarez, B., and Banerjee, R. (2018). Chemical biology of $\mathrm{H}(2) \mathrm{S}$ signaling through persulfidation. Chem. Rev. 118, 1253-1337. doi: 10.1021/acs.chemrev.7b00205

Fitzmaurice, C., Dicker, D., Pain, A., Hamavid, H., Moradi-Lakeh, M., MacIntyre, M. F., et al. (2015). The global burden of cancer 2013. JAMA Oncol. 1, 505-527. doi: 10.1001/jamaoncol.2015.0735

Fruehauf, J. P., and Meyskens, F. L. (2007). Reactive oxygen species: a breath of life or death? Clin. Cancer Res. 13, 789-794. doi: 10.1158/1078-0432.CCR-06-2082

Fu, M., Zhang, W., Wu, L., Yang, G., Li, H., and Wang, R. (2012). Hydrogen sulfide (H2S) metabolism in mitochondria and its regulatory role in energy production. Proc. Natl. Acad. Sci. U.S.A. 109, 2943-2948. doi: 10.1073/pnas. 1115634109

Gai, J. W., Qin, W., Liu, M., Wang, H. F., Zhang, M., Li, M., et al. (2016). Expression profile of hydrogen sulfide and its synthases correlates with tumor stage and grade in urothelial cell carcinoma of bladder. Urol. Oncol. Semin. Orig. Investig. 34, e15-e20. doi: 10.1016/j.urolonc.2015. 06.020

Giuffrè, A., and Vicente, J. B. (2018). Hydrogen sulfide biochemistry and interplay with other gaseous. Oxid. Med. Cell. Longev. 2018:6290931. doi: 10.1155/2018/ 6290931

Goff, B. A., de la Cuesta, R. S., Muntz, H. G., Fleischhacker, D., Ek, M., Rice, L. W., et al. (1996). Clear cell carcinoma of the ovary: a distinct histologic type with poor prognosis and resistance to platinum-based chemotherapy in stage III disease. Gynecol. Oncol. 60, 412-417. doi: 10.1006/gyno.1996.0065

Goubern, M., Andriamihaja, M., Nubel, T., Blachier, F., and Bouillaud, F. (2007). Sulfide, the first inorganic substrate for human cells. FASEB J. 21, 1699-1706. doi: 10.1096/fj.06-7407com

Gout, P. W., Buckley, A. R., Simms, C. R., and Bruchovsky, N. (2001). Sulfasalazine, a potent suppressor of lymphoma growth by inhibition of the $\mathrm{x}(\mathrm{c})$ - cystine transporter: a new action for an old drug. Leukemia 15, 1633-1640. doi: 10. 1038/sj.leu.2402238

Habib, E., Linher-Melville, K., Lin, H. X., and Singh, G. (2015). Expression of xCT and activity of system xc-are regulated by NRF2 in human breast cancer cells in response to oxidative stress. Redox Biol. 5, 33-42. doi: 10.1016/j.redox.2015.03. 003

Hipólito, A., Nunes, S. C., Vicente, J. B., and Serpa, J. (2020). Cysteine aminotransferase (CAT): a pivotal sponsor in metabolic remodeling and an ally of 3-mercaptopyruvate sulfurtransferase (MST) in cancer. Molecules 25:3984. doi: 10.3390/molecules25173984

Hu, L.-F., Lu, M., Hon Wong, P. T., and Bian, J.-S. (2011). Hydrogen sulfide: neurophysiology and neuropathology. Antioxid. Redox Signal. 15, 405-419. doi: $10.1089 /$ ars. 2010.3517

Jayson, G. C., Kohn, E. C., Kitchener, H. C., and Ledermann, J. A. (2014). Ovarian cancer. Lancet 384, 1376-1388. doi: 10.1016/S0140-6736(13)62146-7

Jourdain, A. A., Begg, B. E., Mick, E., Shah, H., Calvo, S. E., Skinner, O. S., et al. (2021). Loss of LUC7L2 and U1 snRNP subunits shifts energy metabolism from glycolysis to OXPHOS. Mol. Cell 81, 1905-1919. doi: 10.1016/j.molcel.2021.02. 033

Kabil, O., and Banerjee, R. (2014). Enzymology of $\mathrm{H}_{2} \mathrm{~S}$ biogenesis, decay and signaling. Antioxid. Redox Signal. 20, 770-782. doi: 10.1089/ars.2013.5339

Kimura, Y., Goto, Y.-I., and Kimura, H. (2010). Hydrogen sulfide increases glutathione production and suppresses oxidative stress in mitochondria. Antioxid. Redox Signal. 12, 1-13. doi: 10.1089/ars.2008.2282

Li, S., and Yang, G. (2015). Hydrogen sulfide maintains mitochondrial DNA replication via demethylation of TFAM. Antioxid. Redox Signal. 23, 630-642. doi: $10.1089 /$ ars.2014.6186

Lopes-Coelho, F., Gouveia-Fernandes, S., Gonçalves, L. G., Nunes, C., Faustino, I., Silva, F., et al. (2016). HNF1B drives glutathione (GSH) synthesis underlying intrinsic carboplatin resistance of ovarian clear cell carcinoma (OCCC). Tumor Biol. 37, 4813-4829. doi: 10.1007/s13277-015-4290-5

Malagrinò, F., Zuhra, K., Mascolo, L., Mastronicola, D., Vicente, J. B., Forte, E., et al. (2019). Hydrogen sulfide oxidation: adaptive changes in mitochondria of sw480 colorectal cancer cells upon exposure to hypoxia. Oxid. Med. Cell. Longev. 2019:8102936. doi: 10.1155/2019/8102936

Mironov, A., Seregina, T., Nagornykh, M., Luhachack, L. G., Korolkova, N., Lopes, L. E., et al. (2017). Mechanism of H 2 S-mediated protection against oxidative stress in Escherichia coli. Proc. Natl. Acad. Sci. U.S.A. 114, 6022-6027. doi: $10.1073 /$ pnas. 1703576114
Módis, K., Coletta, C., Erdélyi, K., Papapetropoulos, A., and Szabo, C. (2013a). Intramitochondrial hydrogen sulfide production by 3-mercaptopyruvate sulfurtransferase maintains mitochondrial electron flow and supports cellular bioenergetics. FASEB J. 27, 601-611. doi: 10.1096/fj.12-216507

Módis, K., Panopoulos, P., Coletta, C., Papapetropoulos, A., and Szabo, C. (2013b). Hydrogen sulfide-mediated stimulation of mitochondrial electron transport involves inhibition of the mitochondrial phosphodiesterase 2A, elevation of cAMP and activation of protein kinase A. Biochem. Pharmacol. 86, 1311-1319. doi: 10.1016/j.bcp.2013.08.064

Nunes, S. C., Lopes-Coelho, F., Gouveia-Fernandes, S., Ramos, C., Pereira, S. A., and Serpa, J. (2018a). Cysteine boosters the evolutionary adaptation to $\mathrm{CoCl} 2$ mimicked hypoxia conditions, favouring carboplatin resistance in ovarian cancer. BMC Evol. Biol. 18:97. doi: 10.1186/s12862-018-1214-1

Nunes, S. C., Ramos, C., Lopes-Coelho, F., Sequeira, C. O., Silva, F., GouveiaFernandes, S., et al. (2018b). Cysteine allows ovarian cancer cells to adapt to hypoxia and to escape from carboplatin cytotoxicity. Sci. Rep. 8:9513. doi: 10.1038/s41598-018-27753-y

Okuno, S., Sato, H., Tamba, M., Wang, H., Sohda, S., Hamada, H., et al. (2003). Role of cystine transport in intracellular glutathione level and cisplatin resistance in human ovarian cancer cell lines. Br. J. Cancer 88, 951-956. doi: 10.1038/sj.bjc. 6600786

Pan, Y., Zhou, C., Yuan, D., Zhang, J., and Shao, C. (2015). Radiation exposure promotes hepatocarcinoma cell invasion through epithelial mesenchymal transition mediated by H2S/CSE pathway. Radiat. Res. 185, 96-105. doi: 10. 1667/RR14177.1

Panza, E., De Cicco, P., Armogida, C., Scognamiglio, G., Gigantino, V., Botti, G., et al. (2015). Role of the cystathionine $\gamma$ lyase/hydrogen sulfide pathway in human melanoma progression. Pigment Cell Melanoma Res. 28, 61-72. doi: $10.1111 / \mathrm{pcmr} .12312$

Polewski, M. D., Reveron-Thornton, R. F., Cherryholmes, G. A., Marinov, G. K., Cassady, K., and Aboody, K. S. (2016). Increased expression of system xc- in glioblastoma confers an altered metabolic state and temozolomide resistance. Mol. Cancer Res. 14, 1229-1242. doi: 10.1158/1541-7786.MCR-16-0028

Prat, J. (2012). Ovarian carcinomas: five distinct diseases with different origins, genetic alterations, and clinicopathological features. Virchows Arch 460, 237 249. doi: 10.1007/s00428-012-1203-5

Reid, B. M., Permuth, J. B., and Sellers, T. A. (2017). Epidemiology of ovarian cancer: a review. Cancer Biol. Med. 14, 9-32. doi: 10.20892/j.issn.2095-3941. 2016.0084

Saed, G. M., Diamond, M. P., and Fletcher, N. M. (2017). Updates of the role of oxidative stress in the pathogenesis of ovarian cancer. Gynecol. Oncol. 145, 595-602. doi: 10.1016/j.ygyno.2017.02.033

Sato, H., Tamba, M., Kuriyama-Matsumura, K., Okuno, S., and Bannai, S. (2000). Molecular cloning and expression of human xCT, the light chain of amino acid transport system xc-. Antioxid. Redox Signal. 2, 665-671. doi: 10.1089/ars.2000. 2.4-665

Schnelldorfer, T., Gansauge, S., Gansauge, F., Schlosser, S., Beger, H. G., and Nussler, A. K. (2000). Glutathione depletion causes cell growth inhibition and enhanced apoptosis in pancreatic cancer cells. Cancer 89, 1440-1447. doi: 10. 1002/1097-0142(20001001)89:7<1440::AID-CNCR5<3.0.CO;2-0

Semenza, G. L. (2012). Hypoxia-inducible factors: mediators of cancer progression and targets for cancer therapy. Trends Pharmacol. Sci. 33, 207-214. doi: 10. 1016/j.tips.2012.01.005

Sen, S., Kawahara, B., Gupta, D., Tsai, R., Khachatryan, M., Farias-eisner, R., et al. (2015). Role of cystathionine $\beta$-synthase in human breast Cancer. Free Radic. Biol. Med. 86, 228-238. doi: 10.1016/j.freeradbiomed.2015.05.024

Senthil, K., Aranganathan, S., and Nalini, N. (2004). Evidence of oxidative stress in the circulation of ovarian cancer patients. Clin. Chim. Acta 339, 27-32. doi: 10.1016/j.cccn.2003.08.017

Sugiyama, T., Kamura, T., Kigawa, J., Terakawa, N., Kikuchi, Y., Kita, T., et al. (2000). Clinical characteristics of clear cell carcinoma of the ovary : a distinct histologic type with poor prognosis and resistance to platinum-based chemotherapy. Cancer 88, 2584-2589. doi: 10.1002/1097-0142(20000601)88: $11<2584$ ::aid-cncr22>3.0.co;2-5

Sun, X., Wang, W., Dai, J., Jin, S., Huang, J., Guo, C., et al. (2017). A long-term and slow-releasing hydrogen sulfide donor protects against myocardial ischemia/reperfusion injury. Sci. Rep. 7:3541. doi: 10.1038/s41598017-03941-0 
Szabo, C., Coletta, C., Chao, C., Módis, K., Szczesny, B., and Papapetropoulos, A. (2013). Tumor-derived hydrogen sulfide, produced by cystathionine$\beta$-synthase, stimulates bioenergetics, cell proliferation, and angiogenesis in colon cancer. PNAS Pharmacol. 110, 12474-12479. doi: 10.1073/pnas. 1306241110

Szczesny, B., Marcatti, M., Zatarain, J. R., Druzhyna, N., Wiktorowicz, J. E., Nagy, P., et al. (2016). Inhibition of hydrogen sulfide biosynthesis sensitizes lung adenocarcinoma to chemotherapeutic drugs by inhibiting mitochondrial DNA repair and suppressing cellular bioenergetics. Sci. Rep. 6:36125. doi: 10.1038/ srep36125

Teng, H., Wu, B., Zhao, K., Yang, G., Wu, L., and Wang, R. (2013). Oxygensensitive mitochondrial accumulation of cystathionine -synthase mediated by Lon protease. Proc. Natl. Acad. Sci. U.S.A. 110, 12679-12684. doi: 10.1073/pnas. 1308487110

Vaupel, P., and Mayer, A. (2007). Hypoxia in cancer: significance and impact on clinical outcome. Cancer Metastasis Rev. 26, 225-239. doi: 10.1007/s10555-0079055-1

Vomund, S., Schäfer, A., Parnham, M. J., Brüne, B., and Von Knethen, A. (2017). $\mathrm{Nrf2}$, the master regulator of anti-oxidative responses. Int. J. Mol. Sci. 18:2772. doi: $10.3390 /$ ijms 18122772

Wang, R. (2012). Physiological implications of hydrogen sulfide: a whiff exploration that blossomed. Physiol. Rev. 92, 791-896. doi: 10.1152/physrev. 00017.2011

Zhou, Y., Tozzi, F., Chen, J., Fan, F., Xia, L., Wang, J., et al. (2012). Intracellular ATP levels are a pivotal determinant of chemoresistance in colon cancer cells. Cancer Res. 72, 304-314. doi: 10.1158/0008-5472.CAN-11-1674
Zivanovic, J., Kouroussis, E., Kohl, J. B., Adhikari, B., Bursac, B., SchottRoux, S., et al. (2019). Selective persulfide detection reveals evolutionarily conserved antiaging effects of S-sulfhydration. Cell Metab. 30, 1152-1170. doi: 10.1016/j.cmet.2019.10.007

Zuhra, K., Tomé, C. S., Forte, E., Vicente, J. B., and Giuffrè, A. (2021). The multifaceted roles of sulfane sulfur species in cancer-associated processes. Biochim. Biophys. Acta Bioenerg. 1862:148338. doi: 10.1016/j.bbabio.2020. 148338

Conflict of Interest: The authors declare that the research was conducted in the absence of any commercial or financial relationships that could be construed as a potential conflict of interest.

Publisher's Note: All claims expressed in this article are solely those of the authors and do not necessarily represent those of their affiliated organizations, or those of the publisher, the editors and the reviewers. Any product that may be evaluated in this article, or claim that may be made by its manufacturer, is not guaranteed or endorsed by the publisher.

Copyright (C) 2021 Nunes, Ramos, Santos, Mendes, Silva, Vicente, Pereira, Félix, Gonçalves and Serpa. This is an open-access article distributed under the terms of the Creative Commons Attribution License (CC BY). The use, distribution or reproduction in other forums is permitted, provided the original author(s) and the copyright owner(s) are credited and that the original publication in this journal is cited, in accordance with accepted academic practice. No use, distribution or reproduction is permitted which does not comply with these terms. 